\title{
Searching for Life on Mars: Degradation of Surfactant Solutions Used in Organic Extraction Experiments
}

\author{
Richard W. Court, Mark R. Sims, ${ }^{2}$ David C. Cullen, ${ }^{3}$ and Mark A. Sephton ${ }^{1}$
}

\begin{abstract}
Life-detection instruments on future Mars missions may use surfactant solutions to extract organic matter from samples of martian rocks. The thermal and radiation environments of space and Mars are capable of degrading these solutions, thereby reducing their ability to dissolve organic species. Successful extraction and detection of biosignatures on Mars requires an understanding of how degradation in extraterrestrial environments can affect surfactant performance. We exposed solutions of the surfactants polysorbate 80 (PS80), Zonyl FS-300, and poly[dimethylsiloxane-co-[3-(2-(2-hydroxyethoxy)ethoxy)propyl]methylsiloxane] (PDMSHEPMS) to elevated radiation and heat levels, combined with prolonged storage. Degradation was investigated by measuring changes in $\mathrm{pH}$ and electrical conductivity and by using the degraded solutions to extract a suite of organic compounds spiked onto grains of the martian soil simulant JSC Mars-1. Results indicate that the proton fluences expected during a mission to Mars do not cause significant degradation of surfactant compounds. Solutions of PS80 or PDMSHEPMS stored at $-20^{\circ} \mathrm{C}$ are able to extract the spiked standards with acceptable recovery efficiencies. Extraction efficiencies for spiked standards decrease progressively with increasing temperature, and prolonged storage at $60^{\circ} \mathrm{C}$ renders the surfactant solutions ineffective. Neither the presence of ascorbic acid nor the choice of solvent unequivocally alters the efficiency of extraction of the spiked standards. Since degradation of polysorbates has the potential to produce organic compounds that could be mistaken for indigenous martian organic matter, the polysiloxane PDMSHEPMS may be a superior choice of surfactant for the exploration of Mars. Key Words: Mars-Life detection-Surfactants—Life Marker Chip. Astrobiology 14, $\mathrm{XXX}-\mathrm{XXX}$.
\end{abstract}

\section{Introduction}

\subsection{The search for organic matter on Mars}

O RGANIC MATTER has yet to be unambiguously detected in rocks on Mars (Glavin et al., 2013; Leshin et al., 2013; Ming et al., 2014), despite expectations that the planet should receive about 12,000 tonnes year ${ }^{-1}$ of carbonaceous micrometeorites (Flynn, 1996), possibly resulting in accumulations of organic matter as high as $60 \mathrm{ppm}$ (Steininger et al., 2012). The failure of the Viking landers to detect meteoritic organic matter in the martian regolith led to suggestions of the presence of an oxidant capable of destroying organic matter upon heating (Biemann et al., 1977; Klein, 1978), with species such as hydrogen peroxide and superoxide ions being proposed (Zent and McKay, 1994; Yen et al., 2000), along with mechanisms such as radiolysis and oxidation (e.g.,
Benner et al., 2000; Kminek and Bada, 2006). In 2008, the presence of perchlorate at $0.5-0.7 \mathrm{wt} \%$ in the northern plains was reported by the Phoenix lander (Hecht et al., 2009; Kounaves et al., 2010). More recently, evidence for oxychlorine species such as perchlorate and/or chlorate has been detected by the Curiosity rover in the Rocknest eolian dust deposit in Gale Crater (Glavin et al., 2013; Leshin et al., 2013), implying a global distribution. Proposed mechanisms of production of perchlorate include ultraviolet photooxidation of chlorides on mineral surfaces (Schuttlefield et al., 2011) and gas-phase oxidation of chlorine species (Catling et al., 2010; Kim et al., 2013), although the latter mechanism is hindered by the apparent lack of a significant chlorine chemistry in the atmosphere of Mars (Villanueva et al., 2013). Alternatively, work has shown the potential for radiolysis of perchlorate via the galactic cosmic ray (GCR) and

\footnotetext{
${ }^{1}$ Department of Earth Science and Engineering, Imperial College London, London, UK.

${ }^{2}$ Space Research Centre, Department of Physics and Astronomy, University of Leicester, Leicester, UK.

${ }^{3}$ Cranfield Health, Cranfield University, Cranfield, UK.
} 
solar energetic particle fluxes to generate additional reactive species, such as hypochlorite $\left(\mathrm{ClO}^{-}\right)$, oxygen $\left(\mathrm{O}_{2}\right)$, and chlorine dioxide $\left(\mathrm{ClO}_{2}\right)$ (Quinn et al., 2013).

The ability of oxychlorine species such as perchlorate to degrade organic species constrains methods for the detection of organic matter on Mars that involve thermal processing of a sample, such as pyrolysis (e.g., Steininger et al., 2012). While the potential for solar heating to generate liquid brines in the shallow subsurface should be noted (Martinez and Renno, 2013, and references therein), the cold, dry environment offered by parts of the martian subsurface is otherwise ideal for the preservation of organic matter. At a depth of about $2 \mathrm{~m}$, the GCR flux has been attenuated sufficiently to favor the survival of organic species over geological timescales (e.g., Kminek and Bada, 2006; Pavlov et al., 2012; Hassler et al., 2014), particularly if the presentday surface has been exposed rather more recently (e.g., Farley et al., 2014), while surface oxidants are expected to be able to penetrate into the regolith to a broadly similar depth (Zent, 1998; Kolb et al., 2002; Parnell et al., 2007). Hope therefore exists that Noachian rocks, deposited in the warmer, wetter climate around $4 \mathrm{Ga}$ (e.g., Carr and Head, 2010), may retain the chemical evidence of martian life.

Past and present missions have generally been restricted to analysis of the surface regolith and lacked the ability to excavate more than a few centimeters. The appreciation that the surface material has experienced significant irradiation and oxidation over geological time has led to the desire to drill into the subsurface, ideally into Noachian rocks containing organic matter and deposited in water-rich environments. The ESA-led ExoMars rover currently under development is intended to have the capacity to drill down as deep as $2 \mathrm{~m}$ into the subsurface. However, the question of the best method to detect organic compounds remains. The Viking landers used a gas chromatograph-mass spectrometer (GC-MS) to separate and identify organic species, with the initial release of organic matter from a sample being accomplished by thermal desorption or pyrolysis (Klein, 1978). However, the increased understanding of the oxidants present in the martian regolith has led to the realization that thermal techniques could be contributing to the degradation of organic species via reaction with perchlorates (Catling et al., 2010; Navarro-González et al., 2010; Steininger et al., 2012; Glavin et al., 2013; Ming et al., 2014). Hence, it has become necessary to develop new, energy- and mass-efficient techniques capable of detecting organic matter in hostile chemical environments.

\subsection{The immunological approach to detection of organic species}

The concept of using antibody-based assays to detect very low concentrations of specific molecules has gained ground in recent years (e.g., Marquette and Blum, 2006; Wang, 2006), including in astrobiological applications (Steele et al., 2001; Parro et al., 2005, 201 1b; Schweitzer et al., 2005; Parnell et al., 2007; Sims et al., 2012). A particular attraction of the technique is its ability to detect specific molecules characteristic of particular environments or sources of organic matter. For example, the detection of aromatic hydrocarbons in a martian sample would suggest a contribution from meteoritic organic matter, while the presence of long-chain $n$-alkanes such as hexadecane would suggest a biological source (e.g., Parnell et al., 2007). However, instruments seeking to detect and characterize organic matter on Mars are faced with the problem of how to extract organic material from its host rock or soil and transport it to a detector. Antibody-based detection requires delivery of target compounds to the antibodies in a compatible solvent mixture. Antibodies tend to be compatible only with aqueous solvents; organic solvents such as dichloromethane (DCM) can denature antibodies and render the detector nonfunctional. Antibody incompatibility with organic solvents poses a problem because many of the organic compounds of interest are nonpolar molecules, including aliphatic and isoprenoidal hydrocarbon biomarkers such as $n$-hexadecane and phytane (Fig. 1) that are almost insoluble in water under normal conditions of pressure and temperature (Parnell et al., 2007; Court et al., 2010; Sephton et al., 2013).

One solution to this problem involves using subcritical water: liquid water at $100-374^{\circ} \mathrm{C}$ but not exceeding $22.05 \mathrm{MPa}$ (Sereewatthanawut et al., 2008). Altering the temperature and pressure of subcritical water changes its polarity and allows it to dissolve nonpolar species such as aliphatic hydrocarbons much more efficiently than under normal conditions (Amashukeli et al., 2008; Aubrey et al., 2008). This technique was to be used on Mars by the proposed Urey instrument (Bada et al., 2005; Aubrey et al., 2008), having been tested by successfully extracting amino acids from an Atacama Desert soil sample (Amashukeli et al., 2007, 2008). However, subcritical water extraction is expensive in terms of mass and energy.

\subsection{Surfactants for extraterrestrial organic extraction}

An alternative method of extraction of both polar and nonpolar compounds under normal conditions involves surfactants. The addition of a non-ionic surfactant such as polysorbate 80 (PS80) to water can result in the formation of micelles, with the hydrophobic "tails" of a PS80 molecule (Fig. 1) aligning to encapsulate a nonpolar hydrocarbon, dramatically raising its solubility in water. This approach has proven popular (e.g., Parro et al., 2011b; Sims et al., 2012). The Life Marker Chip (LMC) instrument formerly under development for the ExoMars rover was to use a solution of $1.5 \mathrm{~g} \mathrm{~L}^{-1}$ PS80 in a 20:80 (v/v) methanol-water mixture. It is able to extract aliphatic and aromatic species spiked onto grains of the Mars analogue JSC Mars-1 (Court et al., 2010, 2012a, 2012b; Sims et al., 2012; Sephton et al., 2013). Testing has also revealed the ability of alternative surfactants, such as the fluorocarbon-based Zonyl FS-300 and the siloxanebased poly[dimethylsiloxane-co-[3-(2-(2-hydroxyethoxy) ethoxy)propyl]methylsiloxane] (PDMSHEPMS) to extract organic species spiked onto samples of JSC Mars-1 (Allen et al., 1998; Court et al., 2010, 2012a). The Signs Of Life Detector (SOLID) series of instruments uses a polysorbate 20-based solvent to extract organic matter from solid samples, with the ability to detect mellitic acid and acidophilic microorganisms in samples of Atacama Desert and Río Tinto Mars-analog materials (Parro et al., 2011a, 2011b; Blanco et al., 2013).

However, it cannot be assumed that experiments that use fresh surfactant solutions will be representative of conditions experienced by an organic-detection experiment on Mars. A surfactant solution transported to Mars will have experienced at least 6-9 months of irradiation by cosmic and solar particles during the flight from Earth. Subsequently, 
FIG. 1. Structures of surfactants and the organic standards spiked on the martian analogue JSC Mars-1.

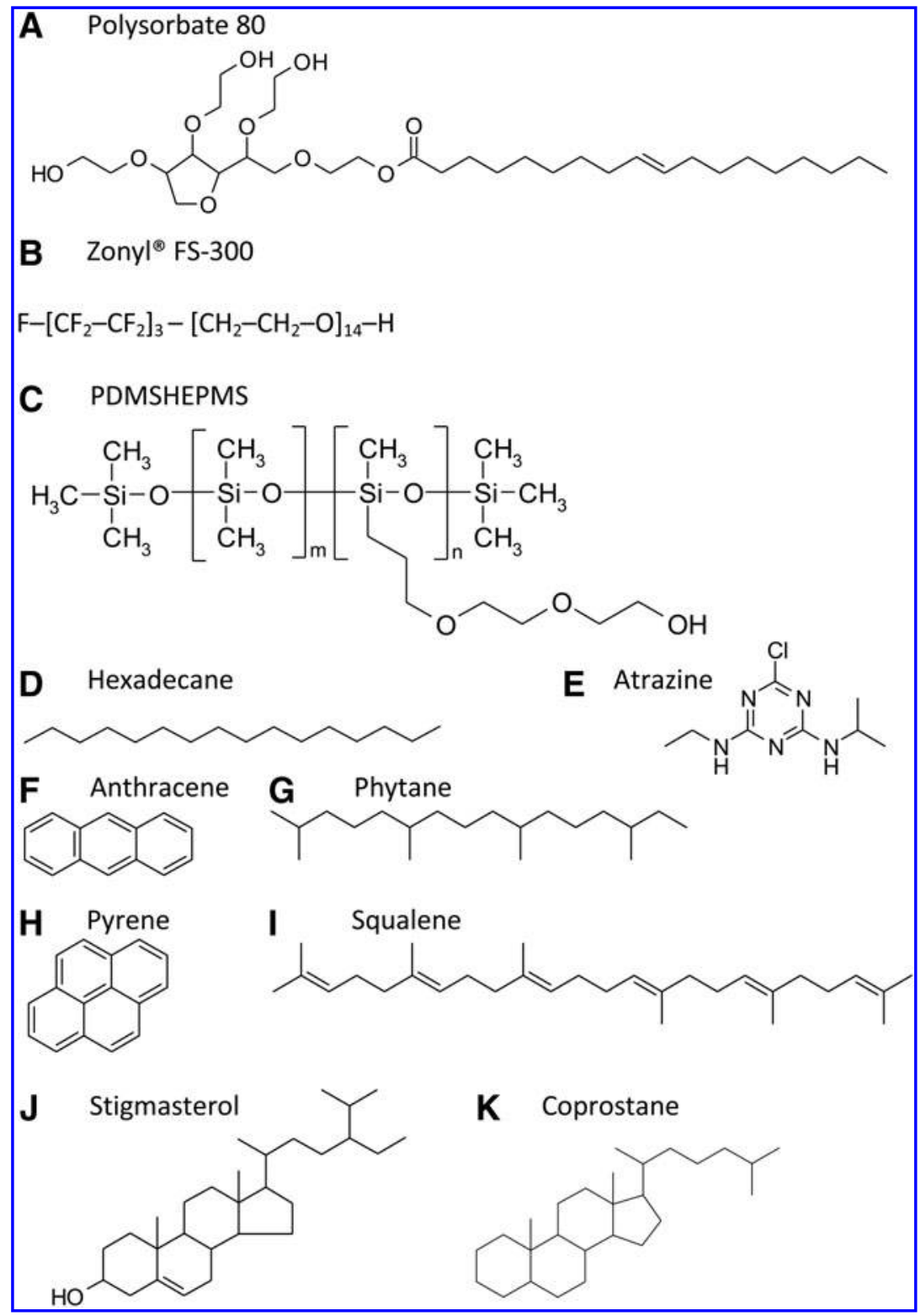

many months may pass on the surface while the host rover explores terrain and characterizes outcrops, before a location that stands the greatest chance of containing detectable organic matter is identified. During this time, the surfactant solution would be exposed to further cosmic and solar particle irradiation, albeit attenuated by the thin atmosphere of Mars (e.g., Dartnell et al., 2007; Parnell et al., 2007, and references therein; Le Postollec et al., 2009), and also to variations in temperature resulting from solar radiation and martian weather. Therefore, the stability of a surfactant solution over many months is of great importance to those who seek to use such a solvent in an instrument with the intent to extract organic matter from the rocks of Mars.

Polysorbates are a well-studied class of surfactants and are commonly used in pharmaceuticals and in food preparation. They are chemically diverse mixtures containing sorbitan polyoxyethylene esters of fatty acids, along with substantial amounts of polyoxyethylene, sorbitan polyoxyethylene, and isosorbide polyoxyethylene fatty acid esters (Ayorinde et al., 2000; Frison-Norrie and Sporns, 2001; Kishore et al., 2011a). Polysorbates are well known to be vulnerable to degradation. Autoxidation of ethylene oxide units is the dominant degradation process that occurs below $40^{\circ} \mathrm{C}$, while hydrolysis of ester bonds becomes more important above this temperature (e.g., Kishore et al., $2011 \mathrm{~b}$, and references therein). Autoxidation produces peroxides, aldehydes, acids, ketones, $n$-alkanes, and fatty acid esters via radical initiation, propagation, and termination reactions (Kerwin, 2008; Kishore et al., 2011b). Autoxidation can be slowed by measures that prevent radical initiation, such as excluding peroxides, heat, light, and oxygen (Yao et al., 2009; Kishore et al., 2011a), or the addition of an antioxidant such as butylated hydroxytoluene (Donbrow, 1987), while removing transition metal ions such as copper can also reduce catalytic effects (Kerwin, 2008). Hydrolysis, which can be both acid- and base-catalyzed (Bates et al., 1973), produces fatty acids (Kerwin, 2008). The rate of hydrolysis can be mitigated by storage under cold conditions 
and protection from light and oxygen (Gilardi-Lorenz, 2006). Degradation should be expected to reduce the ability of polysorbate solutions to act as surfactants (e.g., Donbrow et al., 1978) while also contaminating them with products of the breakdown reactions that may produce a false-positive organic detection. This may be a particular problem for surfactants that closely resemble organic and biological species, such as the polysorbates. In contrast, fluorocarbonand siloxane-based surfactants are expected to be less vulnerable to this problem.

In contrast to PS80, much less information exists on the degradation chemistry of the fluorocarbon-based Zonyl FS300 and the polysiloxane PDMSHEPMS. DuPont describes Zonyl FS-300 as stable following freeze-thaw cycles, capable of performing from $\mathrm{pH} 2-12$, and having a shelf life of 5 years (DuPont, 2005). Zonyl FS-300 contains polyethylene oxide units, which are likely vulnerable to autoxidation in a fashion similar to those of PS80, as described above, but lacks the ester bonds that are vulnerable to hydrolysis in PS80. This suggests that Zonyl FS-300 would be more stable at elevated temperatures, relative to PS80. Autoxidation of ethylene oxide units in Zonyl FS-300 will likely produce species comparable to those produced by the autoxidation of ethylene oxide units in PS80 (Kishore et al., 2011a). The fluorocarbon chain in Zonyl FS-300 is rather inert and resistant to degradation. PDMSHEPMS, like Zonyl FS-300, is not used in pharmaceuticals or in food preparation, and similarly, relatively little information is available regarding its stability and degradation products. Nevertheless, PDMSHEPMS has two units of ethylene oxide in its hydrophilic section, which are likely vulnerable to autoxidation in the same fashion as described for Zonyl FS-300 and PDMSHEPMS. The polysiloxane section, however, is rather inert, with oxidation producing silicon dioxide.

Degradation of the surfactants is expected to be accompanied by variations in solution $\mathrm{pH}$ and electrical conductivity. Organic acids produced by the autoxidation of ethylene oxide units (Kerwin, 2008; Kishore et al., 2011b) should increase acidity and electrical conductivity, although the effects on $\mathrm{pH}$ may be obscured by chemistry related to the degradation of the fluorocarbon and polysiloxane chains, in the cases of Zonyl FS-300 and PDMSHEPMS. Mitigation of the degradation of surfactants may be possible. Ascorbic acid is an effective antioxidant, radioprotector, and free-radical scavenger (Duchesne et al., 1975; Wilson, 1983; El-Nahas et al., 1993; Nair et al., 2001; Aliste and Del Mastro, 2004). At concentrations of $0.1-1.0 \mathrm{wt} \%$, it was found to restrict radiochemistry in carboxymethylcellulose solutions via scavenging of free radicals (Choi et al., 2008) and to protect thymine from damage caused by hydroxyl radicals (Shadyro et al., 2008). It may therefore have the capacity to slow the rate of degradation of surfactant solutions and give them greater tolerance to conditions of heat and radiation. However, ascorbic acid, as a weak acid, is capable of changing the acidity and electrical conductivity of a solution, while also adding organic species that might pose cross-reactivity problems with the antibody-based detector.

\subsection{Thermal and radiation environments}

Maintaining a stable temperature inside a spacecraft en route to Mars can be a challenging proposition, given the insulating properties of space, the intense solar radiation, and the desire not to include active temperature management systems. Instruments must therefore be tolerant of a range of temperatures. Irradiation is a further problem, with a spacecraft and its instruments receiving a wide range of radiation energies and types, including solar protons and highly energetic GCRs (Ryan et al., 1999; e.g., Benton and Benton, 2001). The problem of irradiation of space hardware has long been recognized. Research involving both terrestrial simulation and experimental exposure in lowEarth orbit has investigated whether immunoassay components in a LMC-type instrument could survive the expected radiation environment (Derveni et al., 2012, 2013). These experiments indicated that the expected radiation environments would not pose a threat to the immunoassays; however, this must also be established for the surfactant solutions.

\section{Materials and Methods}

\subsection{Production of surfactant solutions}

Three surfactants-PS80, Zonyl FS-300, and PDMSHEPMS - were used to create a range of solutions, each with the surfactant present at $1.5 \mathrm{~g} \mathrm{~L}^{-1}$. These surfactants were investigated in two forms, firstly as the complete solution of surfactant in 20:80 (v/v) methanol-water and secondly as the surfactant mixed with methanol alone, in both cases with and without $2 \mathrm{~g} \mathrm{~L}^{-1}$ ascorbic acid. This reflects the possibility of storing the solvents separately and mixing the final surfactant solution after arrival on Mars, if it were shown that this was associated with increased surfactant stability. Storage of surfactant alone is not attractive, as all three surfactants are viscous liquids at room temperature and pressure. Maintaining surfactants as solids via refrigeration is also unattractive because of the power, mass, and complexity requirements. The compatibility of $2 \mathrm{~g} \mathrm{~L}^{-1}$ ascorbic acid with the antibody assay used by the LMC experiment to detect the organic species was investigated by performing immunoassays with a number of representative antibodies. These showed that a concentration of $2 \mathrm{~g} \mathrm{~L}^{-1}(11.4 \mathrm{mM})$ of ascorbate had no measureable effect on antibody/assay performance and did not significantly affect the solution $\mathrm{pH}$ or ionic strength (D. Cullen, private communication, 2012).

\subsection{Storage of surfactant solutions}

Surfactant solutions were created in the summer of 2012, with the intent to store them at up to $60^{\circ} \mathrm{C}$ for around a year in the dark. For the stored sample set, a total of 48 surfactant solutions was created, consisting of all 48 combinations of the following parameters (Table 1): $1.5 \mathrm{~g} \mathrm{~L}^{-1}$ of one of PS80, Zonyl FS-300, or PDMSHEPMS; using methanol or 20:80 (v/v) methanol-water as a solvent; with 0 or $2 \mathrm{~g} \mathrm{~L}^{-1}$ of ascorbic acid added as an antioxidant and radioprotector, and stored in the dark at $-20^{\circ} \mathrm{C}, 5^{\circ} \mathrm{C}, 20^{\circ} \mathrm{C}$, or $60^{\circ} \mathrm{C}$. Thermal design considerations of the LMC have concluded that the temperature experienced during flight to Mars would not exceed $60^{\circ} \mathrm{C}$ (ESA private communication, 2012); hence, this was the maximum temperature of storage. Since low temperatures are expected to inhibit degradation, the stability of surfactant solutions at lower temperatures is also of interest. 
Table 1. Details of the Stored Surfactant Solution Sets

\begin{tabular}{|c|c|c|c|c|c|}
\hline \multirow[b]{2}{*}{$\begin{array}{l}\text { Temperature } \\
\left({ }^{\circ} \mathrm{C}\right) \text { of storage }\end{array}$} & \multicolumn{2}{|c|}{ Age (days) of sample set when: } & \multirow[b]{2}{*}{$\begin{array}{l}\text { Surfactant } \\
\left(1.5 \mathrm{~g} \mathrm{~L}^{-1}\right)\end{array}$} & \multirow[b]{2}{*}{ Solvent } & \multirow[b]{2}{*}{$\begin{array}{l}\text { Ascorbic } \\
\text { acid }\left(g L^{-1}\right)\end{array}$} \\
\hline & $\begin{array}{c}\text { Used to extract } \\
\text { spiked JSC Mars-1 }\end{array}$ & $\begin{array}{l}\text { Conductivity and } \\
\text { pH last measured }\end{array}$ & & & \\
\hline-20 & 273 & 384 & PS80 & $\mathrm{MeOH}$ & 0 \\
\hline 5 & 429 & 384 & Zonyl & 20:80 MeOH-water & 2 \\
\hline 20 & 429 & 384 & PDMSHEPMS & & \\
\hline 60 & 122 & 294 & & & \\
\hline
\end{tabular}

Solutions, each about $50 \mathrm{~mL}$ in volume and containing about $75 \mathrm{mg}$ of a surfactant, representing all 48 combinations of listed temperature, surfactant, solvent, and ascorbic acid concentration, were created. Analyses of samples stored at each temperature were performed at intervals as listed (see Section 2.4 for further details). $\mathrm{MeOH}$ indicates methanol.

Surfactant solutions, each about $50 \mathrm{~mL}$ in volume, were stored in borosilicate glass bottles, previously cleaned by baking in air at $500^{\circ} \mathrm{C}$ for around $6 \mathrm{~h}$. The mass of surfactant in the surfactant solutions was about $75 \mathrm{mg}$; the mass of ascorbic acid in the ascorbic acid-containing solutions was about $100 \mathrm{mg}$. Following the creation of each solution, the bottle headspace was purged with nitrogen to exclude atmospheric oxygen and sealed with a polytetrafluoroethylene (PTFE)-lined cap. The cap and its PTFE seal had previously been cleaned by overnight soaking in a $5 \%$ solution of Decon 90, then sonicated in reverse osmosis (RO) water in a Fisher Scientific FB15063 sonic bath, followed by rinsing with copious amounts of RO water to remove traces of the Decon 90 solution.

Atmospheric oxygen incorporated into the solutions and the bottle headspace may have had the capacity to induce additional degradation of the surfactant solutions. This potential problem was minimized by purging the headspace of the bottles with nitrogen and degassing the water with the degassing function on the Fisher FB15063 sonic bath. Complete removal of headspace and dissolved oxygen should not be expected, but effects arising from this oxygen should be common to all the solutions prepared here. Should these surfactant solutions retain the ability to extract organic species spiked onto aliquots of JSC Mars-1, then it would imply that the dissolved oxygen did not significantly reduce the longevity of these solutions under these conditions.

\subsection{Irradiation of surfactant solutions}

Surfactant solutions for irradiation, as well as control counterparts that were not intended to be irradiated, were also created in the summer of 2012. A full set of every combination of surfactant, solvent, and ascorbic acid concentration was not produced because of limited cyclotron time; instead 10 solutions were produced, providing a good cross section of variations in surfactant, solvent, and ascorbic acid concentration. These solutions were also stored in clean borosilicate glass bottles, with their headspaces purged by nitrogen, then stored in the dark at $5^{\circ} \mathrm{C}$ both before and after irradiation.

The radiation environment that could be experienced by LMC hardware during the flight to Mars and subsequent operation on the surface was simulated with proton irradiation at the Scanditronix MC40 cyclotron facility at the University of Birmingham. The surfactant samples were irradiated in their sealed $50 \mathrm{~mL}$ borosilicate glass bottles by a proton beam of $10 \mathrm{~mm}$ diameter, with the beam energy increased to account for attenutation by the borosilicate glass walls of the bottles. Two sample sets were irradiated, one with a baseline fluence of $6.2 \times 10^{11}$ protons $\mathrm{cm}^{-2}$ at a rate of $7.9 \times 10^{8} \mathrm{~cm}^{-2} \mathrm{~s}^{-1}$ and the other with a fluence 5 times more intense, of $3.1 \times 10^{12}$ protons $\mathrm{cm}^{-2}$ at a rate of $2.0 \times 10^{9} \mathrm{~cm}^{-2} \mathrm{~s}^{-1}$, each using $10 \mathrm{MeV}$ protons. The baseline fluence is derived from the SPENVIS-calculated estimate of the displacement damage equivalent particle fluence of $5.4 \times 10^{10}$ protons $\mathrm{cm}^{-2}$, with energies of $10 \mathrm{MeV}$, which would be experienced by the LMC during 296 days of flight, followed by 218 sols on Mars (ESA private communication, 2012). This fluence has been subsequently corrected here for the area of the proton beam $(10 \mathrm{~mm}$ diameter $)$, which irradiated only a small fraction $\left(0.785 \mathrm{~cm}^{2}\right)$ of the crosssectional area of the surfactant solution, calculated at $9 \mathrm{~cm}^{2}$, with the products of irradiation being dispersed throughout the sample by diffusion and convection.

\subsection{Measurements during storage}

During storage of the samples, $\mathrm{pH}$ and conductivity of sample aliquots were measured (Table 2) with a Hanna Instruments HI-991301N pH/conductivity meter with experimentally determined precisions of \pm 0.3 for $\mathrm{pH}$ of a $\mathrm{pH} 7.01$ calibration solution and of $\pm 2 \mathrm{mS} \mathrm{m}^{-1}$, $\pm 0.2 \%$, for conductivity of a $1281 \mathrm{mS} \mathrm{m}^{-1}$ calibration solution. Measurements of $\mathrm{pH}$ are not reported for the non-aqueous methanol solutions because of the difficulty of calibration for nonaqueous solutions.

Infrared spectra of the solutions were also acquired with a Smart Orbit attenuated total reflectance accessory attached to a Thermo-Nicolet 5700 Fourier transform infrared spectrometer. It was hoped that this might reveal variations in surfactant chemistry, but no spectral differences were observed. Hence, these data are not displayed or discussed further. Visible changes in solution color (Fig. 2) are described below where appropriate. Following photography and measurement of sample conductivity and $\mathrm{pH}$, the sample bottle headspaces were purged with nitrogen and returned to storage in the dark at the appropriate temperatures.

\subsection{Spiking and extraction of JSC Mars-1}

During storage, aliquots of each sample were removed for use in an extraction experiment. The objective was to test the ability of these surfactant solutions, following storage and/or irradiation, to extract a range of polar and nonpolar 


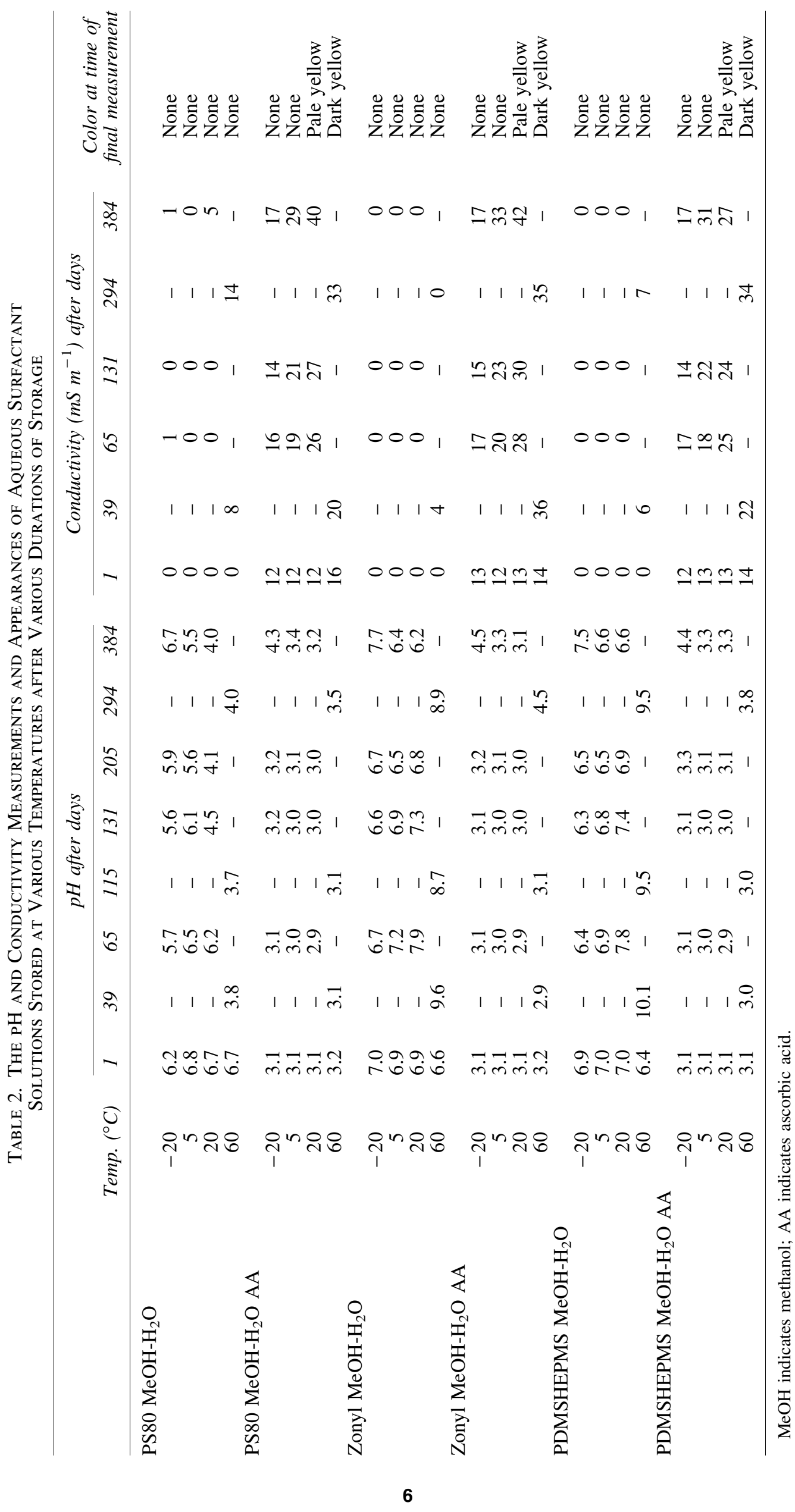




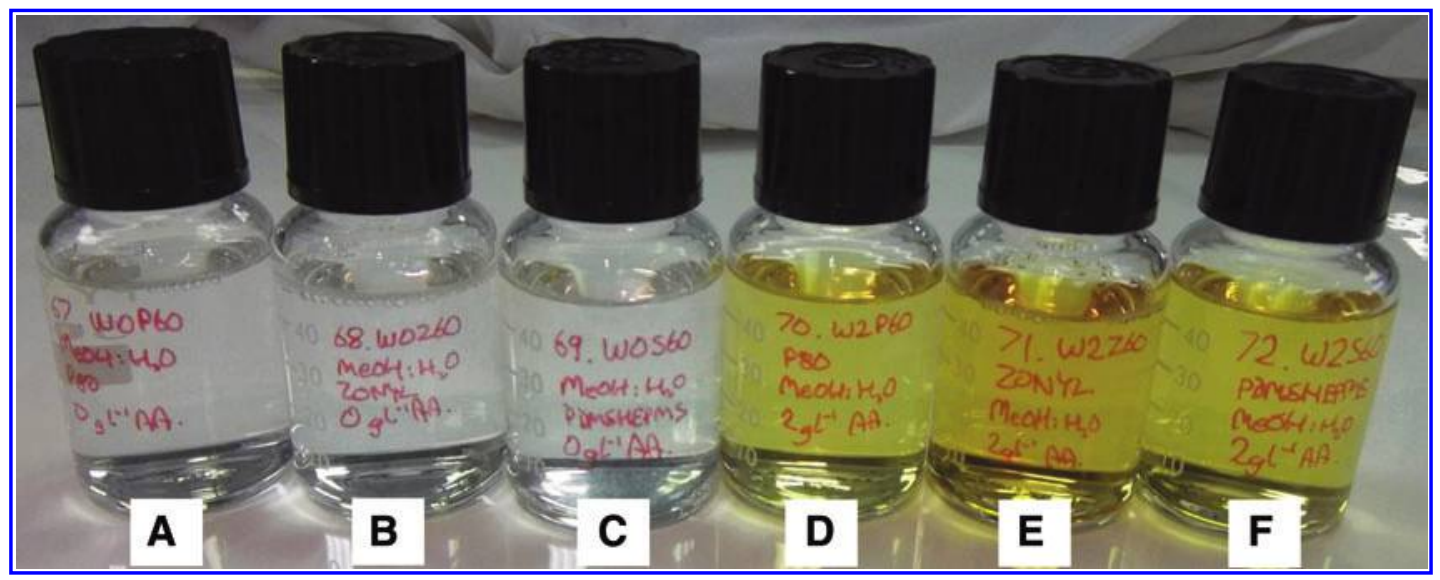

FIG. 2. The discoloration of $1.5 \mathrm{~g} \mathrm{~L}^{-1}$ surfactant solutions in methanol-water following 294 days of storage at $60^{\circ} \mathrm{C}$. From left to right: (A) PS80 without ascorbic acid; (B) Zonyl FS-300 without ascorbic acid; (C) PDMSHEPMS without ascorbic acid; (D) PS80 with $2 \mathrm{~g} \mathrm{~L}^{-1}$ ascorbic acid; (E) Zonyl FS-300 with $2 \mathrm{~g} \mathrm{~L}^{-1}$ ascorbic acid; (F) PDMSHEPMS with $2 \mathrm{~g} \mathrm{~L}{ }^{-1}$ ascorbic acid. (Color images available online at www.liebertonline.com/ast)

organic standards spiked onto the surfaces of the martian analogue JSC Mars-1 (Allen et al., 1998; Court et al., 2010, 2012a, 2012b). Samples of JSC Mars-1, $500 \mathrm{mg}$ in mass, were spiked with $10 \mu \mathrm{g}$ of each of eight standards. The JSC Mars-1 was cleaned before this experiment by ultrasonic extraction, first with a 93:7 (v/v) mixture of DCM and methanol, then with deionized water, to remove any preexisting contaminants. The standards used were the aliphatic hydrocarbons hexadecane, phytane, and squalene; the aromatic hydrocarbons anthracene and pyrene; the steroids coprostane and stigmasterol; and atrazine (Fig. 1), reflecting a range of organic biomarkers with different structures and solubilities in water. Atrazine was included not as a potential biomarker but as a control marker, representing a structure not expected to be found on Mars. Its high solubility in aqueous solvents also gives it an additional role as an internal standard capable of revealing uncertainties associated with quantification of the recoveries of the other standards.

These standards were added to the samples of JSC Mars-1 as solution in methanol. The methanol-wet JSC Mars-1 aliquots were allowed to dry overnight in a hotbox at $35^{\circ} \mathrm{C}$, after which the test tubes were agitated to even out the distribution of spiked and non-spiked JSC Mars-1 grains. To each spiked aliquot of JSC Mars-1, $3 \mathrm{~mL}$ of the appropriate surfactant solution was added. For the surfactant solutions in which methanol-water was used as a solvent, the $3 \mathrm{~mL}$ could be taken directly from the stored sample, while for those samples stored by using methanol alone without water, $1.8 \mathrm{~mL}$ of stored methanol-based solution was taken and added to $7.2 \mathrm{~mL}$ of $\mathrm{RO}$ water, to make $9 \mathrm{~mL}$ of $20: 80$ methanol-water-based surfactant solution. Subsequently, $3 \mathrm{~mL}$ of this solution was introduced to the spiked JSC Mars-1 aliquot.

Each test tube containing spiked JSC Mars-1 and the added surfactant solution was sonicated for $10 \mathrm{~min}$ with the FB-15063 sonic bath. This reflects the design of the LMC, where sonication was intended to be used to encourage dissolution of organic species (Sims et al., 2012). Following sonication, the test tubes were centrifuged at $2500 \mathrm{rpm}$ for 5 min to settle suspended particulates, after which the su- pernatant was pipetted into a separate clean glass test tube. Two further cycles of addition of surfactant solution, sonication, centrifugation, and pipetting of the supernatant then followed. The three extracts produced by this process were subsequently merged into one, approximately $9 \mathrm{~mL}$ in volume. Despite centrifuging, these solutions contained suspended JSC Mars-1, produced by the pulverization of grains by ultrasonic agitation. The solutions were therefore pipetted into clean glass syringes and passed through PTFEmembrane syringe filters possessing a $0.2 \mu \mathrm{m}$ pore size. The LMC design also includes a filter to eliminate suspended material (Sims et al., 2012). These aqueous solutions were unsuitable for direct analysis by GC-MS, so liquid-liquid extraction was performed to transport the dissolved standards from the aqueous phase to an organic solvent, DCM, amenable to analysis by GC-MS. Liquid-liquid extraction was performed by adding about $5 \mathrm{~mL}$ of DCM to the aqueous solutions, followed by mixing with a Sonics \& Materials, Inc., VCX-130 sonic probe. Separation of the organic and aqueous solvents was achieved with a centrifuge and a clean separating funnel. This liquid-liquid extraction procedure was performed three times to minimize the loss of the standards, with previous testing having shown that this protocol was effective in minimizing losses of dissolved standards (Court et al., 2010, 2012a, 2012b).

The volume of DCM produced by liquid-liquid extraction was reduced to $1 \mathrm{~mL}$ by evaporation under a stream of nitrogen. One microliter of this was injected onto the Agilent HP-5MS column on a GC-MS, comprising an Agilent 7890N gas chromatograph and a 5975C mass selective detector. The gas chromatograph oven was initially held at $50^{\circ} \mathrm{C}$ for $1 \mathrm{~min}$, then heated at $4^{\circ} \mathrm{C} \min ^{-1}$ to $310^{\circ} \mathrm{C}$, where it was held for $20 \mathrm{~min}$, for a total duration of $86 \mathrm{~min}$. The standards were identified by reference to the NIST 08 mass spectral database, and the retention times for this instrumental configuration were established by previous runs of the individual standards. Further samples, consisting of $10 \mu \mathrm{g}$ of each of the eight standards dissolved in DCM, were run as external standards, demonstrating the chromatographic responses of a concentration of $10 \mu \mathrm{g} \mathrm{mL}^{-1}$ of each compound and enabling the ability of the surfactant solutions to recover the standards 


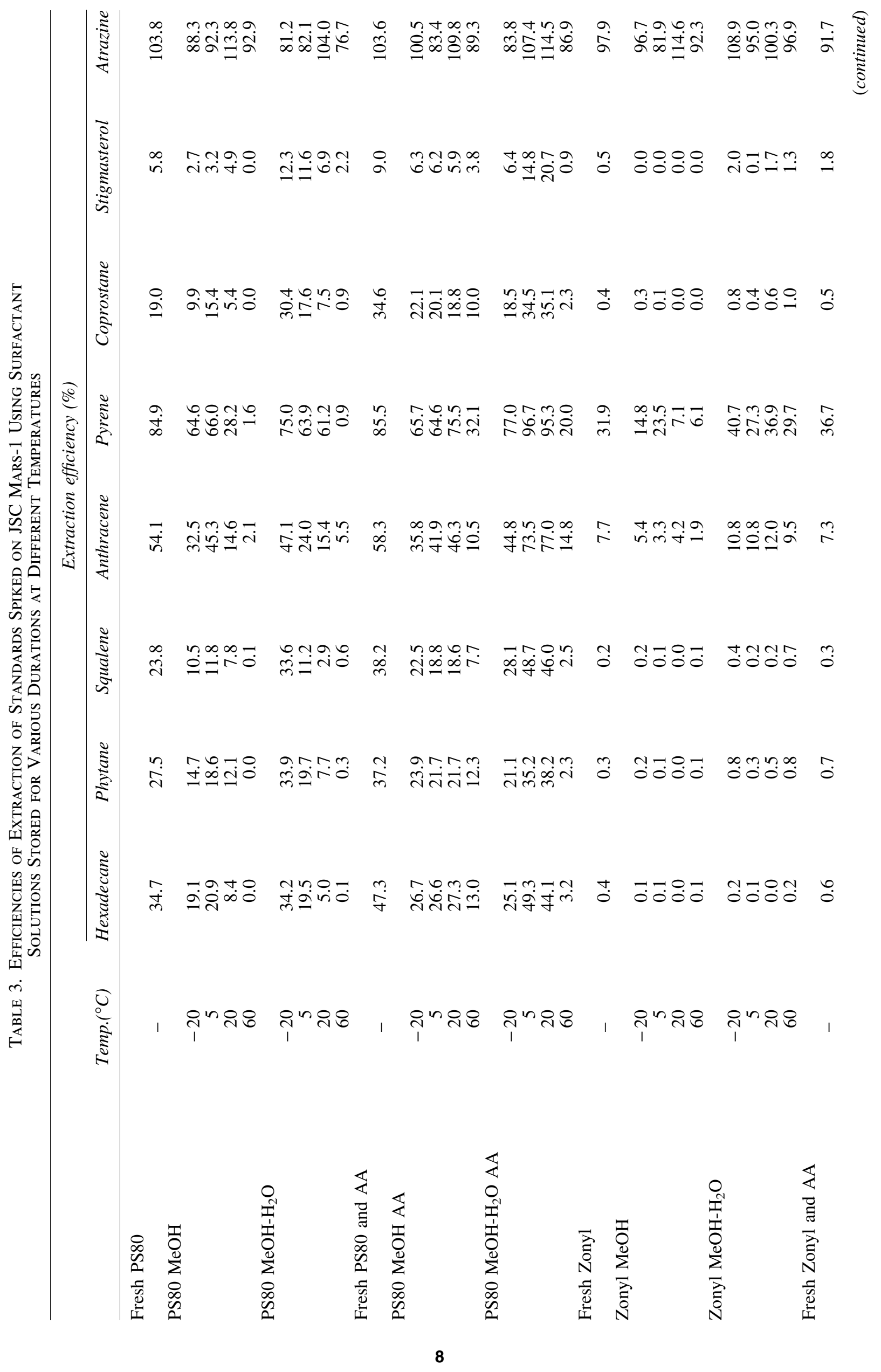




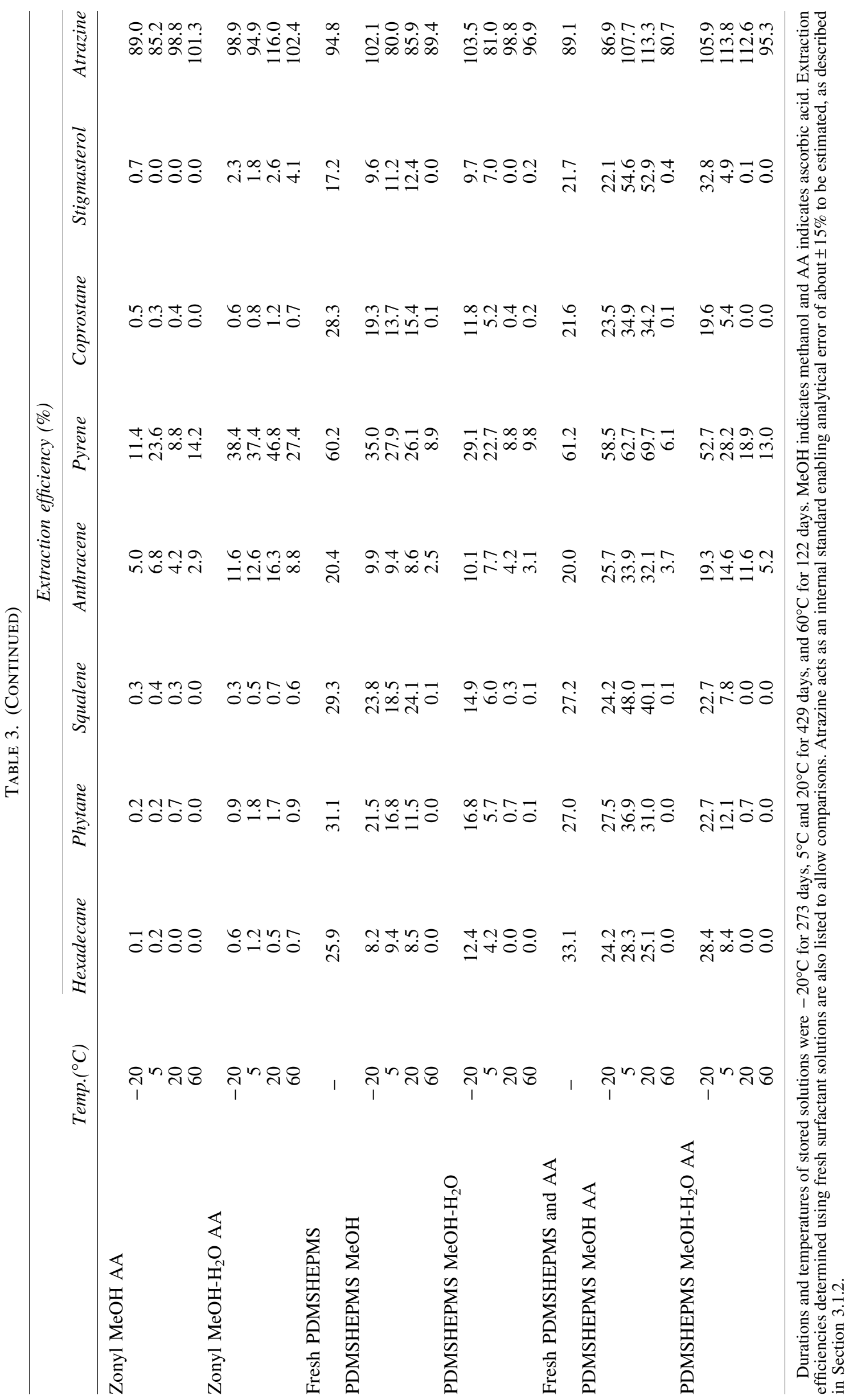


from the JSC Mars- 1 to be calculated as a percentage relative to the original spiked mass. Samples of JSC Mars-1 cleaned as described above but not exposed to the set of standards were also subjected to the extraction and GC-MS analysis, to act as controls. No significant amounts of organic compounds were extracted from these cleaned samples, demonstrating the efficacy of the cleaning procedure and the absence of significant contamination.

\section{Results}

\subsection{Stored surfactant solutions}

3.1.1. Electrical conductivity, $\mathrm{pH}$, and appearance. Table 2 displays variations in the electrical conductivity, $\mathrm{pH}$, and appearance of the aqueous surfactant solutions, as measured at various points during storage. The data for each combination of surfactant, solvent, and ascorbic acid combination at day 1 can be regarded as representing the baseline properties immediately after production of the solution. The samples stored at $60^{\circ} \mathrm{C}$ were produced about 90 days after those stored at lower temperatures, hence the collection of $\mathrm{pH}$ and conductivity data after different durations. Measurements of conductivity and observations of discoloration of the methanol-based solutions were also acquired, but no electrical conductivity or discoloration was detected, with two exceptions. The first was the solution of Zonyl FS-300 and ascorbic acid stored in methanol at $60^{\circ} \mathrm{C}$ for 294 days, which displayed a pale yellow color but possessed no measureable electrical conductivity. The second exception was the solution of PS80 and ascorbic acid stored in methanol at $60^{\circ} \mathrm{C}$ for 294 days, which possessed a darker yellow color and an electrical conductivity of $2 \mathrm{mS} \mathrm{m}^{-1}$.

Solutions of all three surfactants in methanol-water without ascorbic acid are close to neutral $\mathrm{pH}$ upon production. Prolonged storage results in acidification of the warmer PS80 solutions, with the samples stored at $60^{\circ} \mathrm{C}$ developing a $\mathrm{pH}$ around 4.0, while solutions of Zonyl FS-300 and PDMSHEPMS retain $\mathrm{pH}$ values around neutral upon subsequent storage, except those stored at $60^{\circ} \mathrm{C}$, which instead showed an increase in $\mathrm{pH}$ to around 9-10. Aqueous solutions containing ascorbic acid all initially showed a $\mathrm{pH}$ of around 3.1, which is attributed to the dissociation of ascorbic acid. Subsequent storage resulted in no significant change in $\mathrm{pH}$, except for samples stored at $60^{\circ} \mathrm{C}$, where a poorly defined tendency for the $\mathrm{pH}$ to increase to around $\mathrm{pH}$ 4 is apparent.

Aqueous solutions lacking ascorbic acid possessed an electrical conductivity of $0 \mathrm{mS} \mathrm{m} \mathrm{m}^{-1}$ immediately after production. Subsequent storage resulted in significant electrical conductivity developing only in the solutions stored at elevated temperatures, reaching $14 \mathrm{mS} \mathrm{m}^{-1}$ in the case of PS80 in methanol-water stored at $60^{\circ} \mathrm{C}$. Solutions with ascorbic acid present showed initial conductivities around $12-16 \mathrm{mS} \mathrm{m}^{-1}$, with subsequent storage causing an increase to around $40 \mathrm{mS} \mathrm{m}^{-1}$ in the case of the hot, $60^{\circ} \mathrm{C}$ solutions. All aqueous solutions stored at $-20^{\circ} \mathrm{C}$ and $5^{\circ} \mathrm{C}$ retained a clear, colorless appearance throughout storage. However, the solutions of surfactant and ascorbic acid in methanolwater stored at $20^{\circ} \mathrm{C}$ showed a gradual change to a clear yellow color. At $60^{\circ} \mathrm{C}$, this behavior was more pronounced, with all aqueous solutions containing ascorbic acid being a clear yellow-brown color (Fig. 2).
3.1.2. Extractions of spiked JSC Mars-1 using stored surfactant solutions. Samples of the surfactant solutions were removed during storage and used to extract samples of the Mars analogue JSC Mars-1 that had been spiked with organic standards as described in Section 2.5. The efficiencies of extraction, measured as percentages relative to the original spiked mass of each standard, are displayed in Table 3 and Figs. 3-5. "Fresh" surfactant solutions are ones made up immediately before the extraction experiments were performed. The listed extraction efficiencies contain a margin of uncertainty that can be characterized by using the extraction efficiencies of atrazine, which, being watersoluble, should be expected to be recovered at $100 \%$ efficiency by all surfactant solution compositions, regardless of their state of thermal degradation. The atrazine recoveries listed in Table 3 have a mean of $96.6 \%$ and a standard deviation of $10.6 \%$. We therefore assigned a $\pm 15 \%$ uncertainty to the calculated extraction efficiencies of the other spiked standards, as illustrated by error bars in Figs. 3-5.

With this margin of uncertainty in mind, inspection of these data reveals a clear general trend of decreasing recoveries of the spiked standards with increasing temperature. Fresh PS80 gives extraction efficiencies around 25-35\% for aliphatic hydrocarbons, 50-80\% for aromatic hydrocarbons, and 5-20\% for the steroids. In contrast, storage at $60^{\circ} \mathrm{C}$ results in recoveries of aliphatic hydrocarbons and steroids that rarely exceed 5\%. A similar relationship is apparent for PDMSHEPMS. Interpretation of the data for Zonyl FS-300 is hindered by the universally low extraction efficiencies reported, with recoveries rarely exceeding $1 \%$ for aliphatic hydrocarbons and steroids, matching those observed during a previous investigation into Zonyl FS-300 at comparable concentrations (Court et al., 2012a). This investigation required long durations of storage and was initiated before the suitable concentrations of Zonyl FS-300 were established by Court et al. (2012a). Inspection of Fig. 4 shows that increasing temperature of storage of Zonyl FS300 in methanol, with or without ascorbic acid, is associated with a general decrease in recovery of the aromatic standards, but this relationship is not apparent for storage in methanol-water.

The data do not show any clear relationships between extraction efficiency and the nature of the stored solvent, suggesting that the separate storage of water and methanol does not offer any clear advantages or disadvantages over storage as a mixture. The data for PS80 and PDMSHEPMS show a tendency for the presence of ascorbic acid to be associated with superior extraction efficiencies in certain solution configurations, such as PS80 stored in methanolwater at $5^{\circ} \mathrm{C}$ or $20^{\circ} \mathrm{C}$ and PDMSHEPMS stored in methanol at the same temperatures (Figs. 3 and 5), yet in other solution compositions, no clear benefit is apparent.

An alternative method of gauging the ability for the surfactant solutions to extract the spiked standards involved inspection of the chromatograms of the extracts of the surfactant solutions for peaks representative of the surfactant molecules, following the assumption that a decreased prominence of these peaks would reflect a decreased abundance of surfactant molecules in the stored solutions, resulting from degradation. However, this method was unsuccessful, as it was found that the GC-MS injector was either too hot for surfactant molecules to survive injection without breaking 


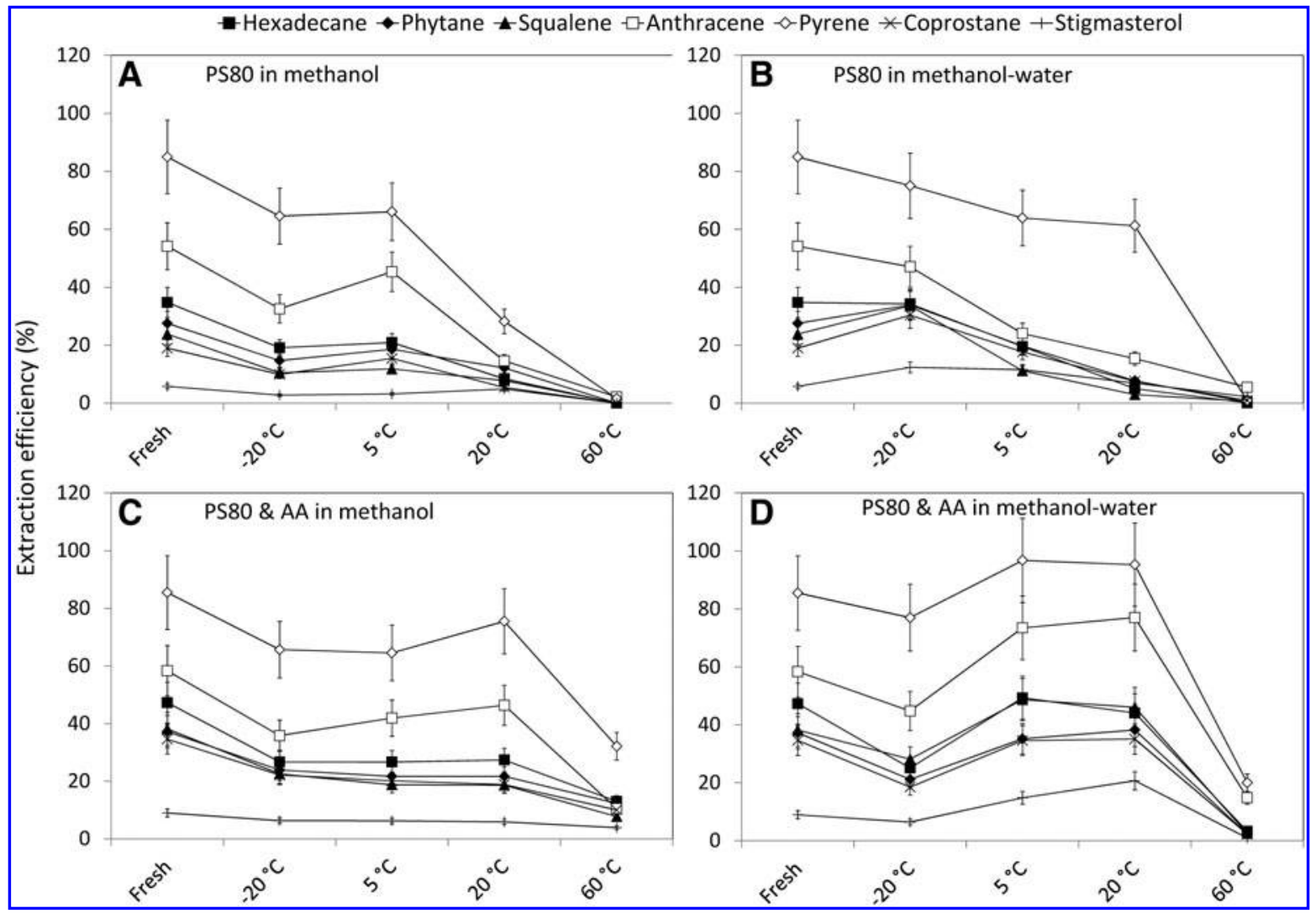

FIG. 3. The extraction efficiencies for organic standards spiked onto JSC Mars-1 and then extracted using PS80 solutions stored at various temperatures for different durations, expressed as percentages of each spiked mass of $10 \mu \mathrm{g}$ recovered, as determined by a comparison of the chromatographic responses of the sample and of $10 \mu \mathrm{g}$ of standard injected directly into the GC-MS. Data for the water-soluble atrazine is excluded to improve clarity. Extraction efficiencies calculated for "fresh" solutions represent PS80 solutions made up immediately before use. Error bars of $\pm 15 \%$ are derived from the distribution of the recoveries of water-soluble atrazine. Temperatures and durations of storage were $-20^{\circ} \mathrm{C}$ for 273 days, $5^{\circ} \mathrm{C}$ and $20^{\circ} \mathrm{C}$ for 429 days, and $60^{\circ} \mathrm{C}$ for 122 days. AA stands for ascorbic acid, and methanol-water indicates a 20:80 (v/v) mixture of methanol and water. In general, the highest extraction efficiencies are seen in the solutions stored at the lowest temperatures.

down into smaller fragments or too cold to yield reproducible vaporization of the surfactant molecules, and no reliable data were obtained.

\subsection{Irradiated surfactant solutions}

For the irradiation experiments, nine different solutions were produced, representing a cross section of combinations of surfactant, solvent, and ascorbic acid, and then separated into 22 different aliquots. Eleven of these were irradiated, with the others used as nonirradiated controls. Following irradiation, all samples were stored at $5^{\circ} \mathrm{C}$ for 174 days before being used to extract samples of JSC Mars-1 spiked with organic standards, following the procedure described in Section 2.5.

3.2.1. Electrical conductivity, $\mathrm{pH}$, and appearance of irradiated surfactant solutions. After storage at $5^{\circ} \mathrm{C}$ for 174 days in the dark, a sample of each solution was tested for $\mathrm{pH}$ and electrical conductivity by using the procedure outlined in Section 3.1.1. No electrical conductivity was measured in any sample, regardless of the radiation fluence experienced. This matches the observations of the stored samples described in Section 3.1.1, where electrical conductivity was only detected in samples for which water-methanol was used as a solvent and that contained ascorbic acid, a combination that was not tested here because of the limited cyclotron time available. Measurements of $\mathrm{pH}$ do not show significant variations between irradiated samples and their nonirradiated counterparts, all being close to $\mathrm{pH} 7.0$. Overall, there is no evidence that irradiation has caused significant changes to sample $\mathrm{pH}$ or conductivity. This conclusion is supported by the absence of changes in the appearance of the solutions following irradiation, with all samples retaining their clear, colorless appearances.

3.2.2. Extractions of spiked JSC Mars-1 using irradiated surfactant solutions. The extraction efficiencies of spiked JSC Mars-1 by surfactant solutions subjected to irradiation followed by storage at $5^{\circ} \mathrm{C}$ for 174 days are displayed in Table 4 and Fig. 6. Irradiated solutions of PS80 in methanol, with or without ascorbic acid, show recoveries of the aliphatic hydrocarbons hexadecane, phytane, and squalene that are generally greater than those achieved when using lessirradiated solutions. A similar relationship is seen for PDMSHEPMS in methanol, again with or without ascorbic acid. For PS80 stored in methanol-water, however, irradiation is associated with a general decrease in recovery of 


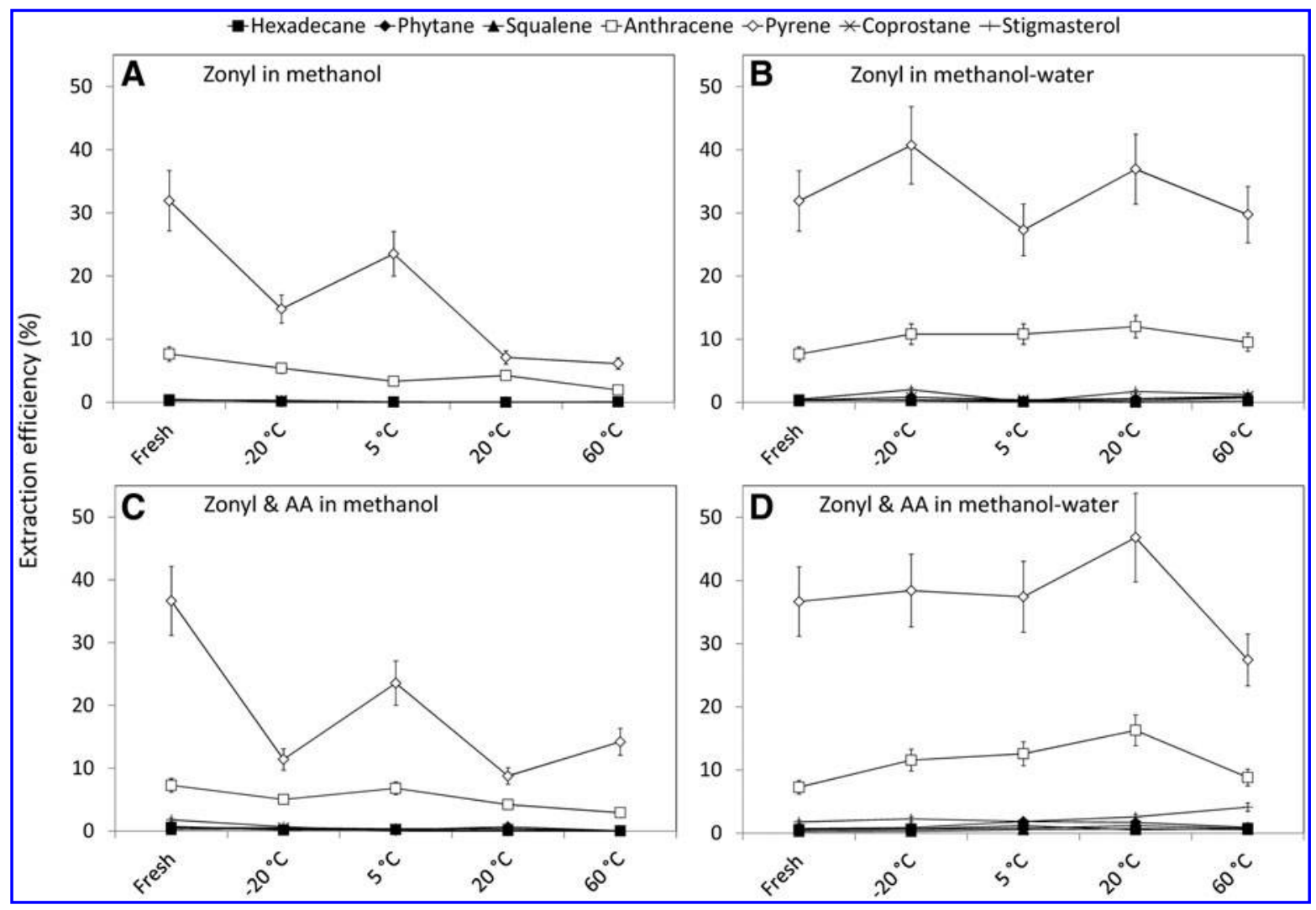

FIG. 4. Extraction efficiencies for organic standards spiked onto JSC Mars-1 and then extracted using Zonyl FS-300 solutions stored at various temperatures for different durations, expressed as percentages of each spiked mass of $10 \mu \mathrm{g}$ recovered, as determined by a comparison of the chromatographic responses of the samples and of $10 \mu \mathrm{g}$ of standard injected directly into the GC-MS. Data for the water-soluble atrazine is excluded to improve clarity. Extraction efficiencies calculated for "fresh" solutions represent Zonyl FS-300 solutions made up immediately before use. Error bars of $\pm 15 \%$ are derived from the distribution of the recoveries of water-soluble atrazine. Durations of storage were $-20^{\circ} \mathrm{C}$ for 273 days, $5^{\circ} \mathrm{C}$ and $20^{\circ} \mathrm{C}$ for 429 days, and $60^{\circ} \mathrm{C}$ for 122 days. AA stands for ascorbic acid, and methanol-water indicates a 20:80 (v/v) mixture of methanol and water. In general, Zonyl FS-300 solutions resulted in very low extraction efficiencies, typically less than $1 \%$ for the aliphatic hydrocarbons and steroids.

standards, although it should be noted that in both cases the percentage recoveries of the standards are high and indicate successful recovery despite the conditions of irradiation and storage experienced.

\section{Implications for Space Missions Involving Surfactant Solutions}

\subsection{Conditions of storage of surfactant solutions in extraterrestrial environments}

4.1.1. Temperature of storage. These data indicate that temperature of storage is the most potent influence on the recovery of organic matter. Prolonged exposures to $60^{\circ} \mathrm{C}$ greatly reduced the ability of PS80 and PDMSHEPMS to extract the organic standards spiked onto the martian analogue JSC Mars-1. A similar effect is also hinted at by the data for aromatic hydrocarbons extracted with Zonyl FS300 , although the relationship is not entirely clear because of the low efficiencies of extraction of the aliphatic hydrocarbons and steroids achieved with these surfactant concentrations. The highest extraction efficiencies are obtained from the samples stored at $-20^{\circ} \mathrm{C}$, the coldest temperature of storage employed here, and the data show a general trend that can be summarized as "the colder, the better." This can be understood in terms of kinetics and the activation energies necessary for reactions to occur. At lower temperatures, fewer molecules have sufficient energy to engage in the degradation reactions; hence the rate of reaction is lower. This principle predicts that even better preservation of the surfactant solutions would occur at temperatures below $-20^{\circ} \mathrm{C}$.

4.1.2. Duration of storage. While storage temperature is the dominant influence on the degradation of the surfactant solutions, the $\mathrm{pH}$ and electrical conductivity data also show relationships between duration of storage and solution chemistry, and it seems reasonable to assume that a particular level of degradation could be achieved by either brief storage at high temperatures or by prolonged storage at lower temperatures. The data of Table 3 do not allow the details of such a relationship to be easily inferred, because both temperature of storage and duration of storage vary. If the degradation of surfactant solutions could be described by a simple Arrhenius factor or half-life, reflecting the gradual breakdown of surfactant molecules at various rates at various temperatures, then Table 3 could be used to produce a 


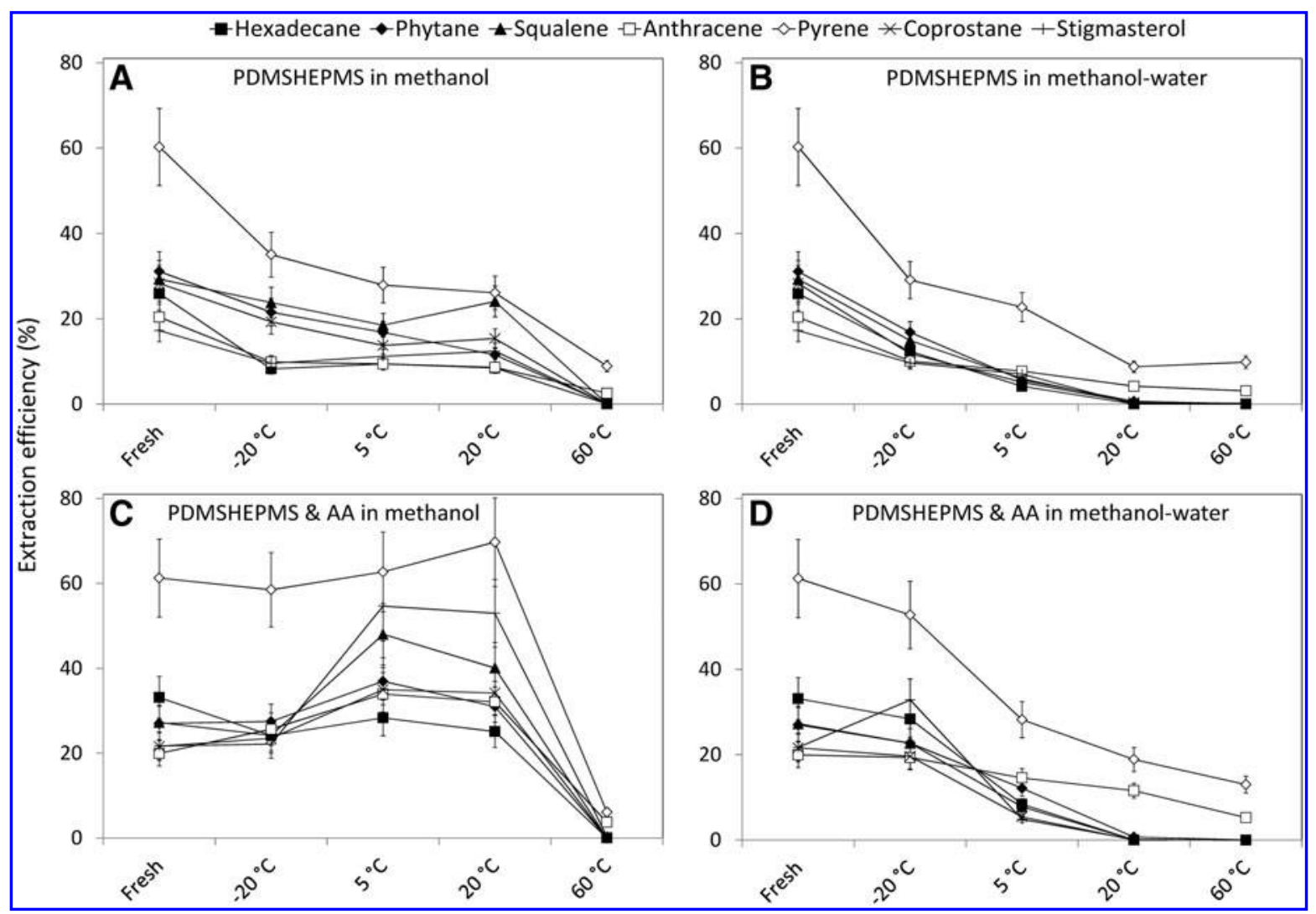

FIG. 5. Extraction efficiencies for organic standards spiked onto JSC Mars-1 and then extracted using PDMSHEPMS solutions stored at various temperatures for different durations, expressed as percentages of each spiked mass of $10 \mu \mathrm{g}$ recovered, as determined by a comparison of the chromatographic responses of the samples and of $10 \mu \mathrm{g}$ of standard injected directly into the GC-MS. Data for the water-soluble atrazine is excluded to improve clarity. Extraction efficiencies calculated for "fresh" solutions represent PDMSHEPMS solutions made up immediately before use. Error bars of $\pm 15 \%$ are derived from the distribution of the recoveries of water-soluble atrazine. Temperatures and durations of storage were $-20^{\circ} \mathrm{C}$ for 273 days, $5^{\circ} \mathrm{C}$ and $20^{\circ} \mathrm{C}$ for 429 days, and $60^{\circ} \mathrm{C}$ for 122 days. AA stands for ascorbic acid, and methanol-water indicates a 20:80 (v/v) mixture of methanol and water. The data show a general trend of decreasing recoveries with increasing temperature of storage.

general model of degradation, allowing the extraction efficiencies of each organic standard to be predicted across the range of durations and temperatures described.

However, it does not appear likely that the degradation can be described so simply. Section 1.3 describes two main degradation pathways, with autoxidation of ethylene oxide units being the dominant process occurring below $40^{\circ} \mathrm{C}$, while hydrolysis is more important above this temperature. The different temperature dependences of these two reactions suggest that degradation across the range of temperatures used here cannot be described by a simple Arrhenius equation. Nevertheless, the data allow important conclusions to be made. Even a relatively brief period of storage of 122 days at $60^{\circ} \mathrm{C}$ is sufficient to severely degrade the abilities of the solutions to extract the suite of organic standards, indicating that longer storage would see even less-efficient extraction. Similarly, prolonged storage at $5^{\circ} \mathrm{C}$ for 429 days resulted in the solutions retaining much of the extraction abilities shown by the freshly produced surfactant solutions, indicating that storage for less time would see improved extraction efficiencies. Hence, these data support a conclusion that storage temperature is much more influential than storage duration on surfactant solution extraction capabilities.
4.1.3. Radiation environment. Variations in the recovery of the spiked standards when using irradiated surfactant solutions are displayed in Fig. 6 and Table 4. As noted in Section 3.2.2, various relationships between efficiency of recovery of the spiked standards and radiation fluence are apparent, with irradiation being generally associated with increases in the recovery of aliphatic hydrocarbons. This is an unexpected relationship, given the expectation that production of hydroxyl radicals via the radiolysis of water might lead to increased degradation of surfactant molecules and hence reduced rates of recovery, and its cause is unclear. Nevertheless, it can be confidently stated that these levels of irradiation of the surfactant solutions do not result in decreased extraction efficiencies capable of causing failure of a LMC-type instrument. Indeed, the similarities between the extraction efficiencies obtained for these irradiated samples and their nonirradiated counterparts, and the "fresh" and $5^{\circ} \mathrm{C}$ stored solutions (Table 3, Figs. 3-5), suggests that the 174 days of storage at $5^{\circ} \mathrm{C}$ has had a greater effect on the ability of the surfactant solutions to extract the spiked standards than any of the irradiation experiments. In these conditions, heat is a more potent degrader of surfactants than radiation. 


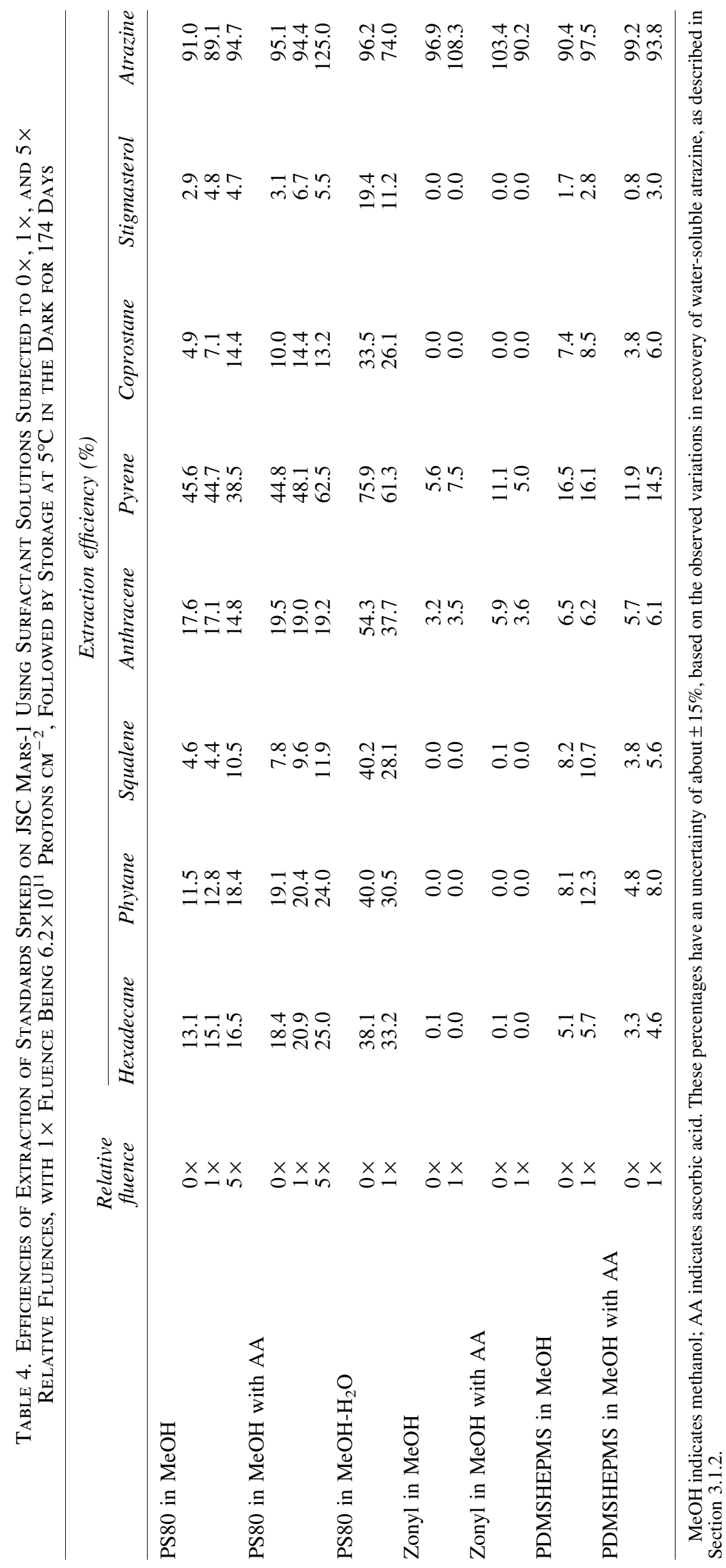




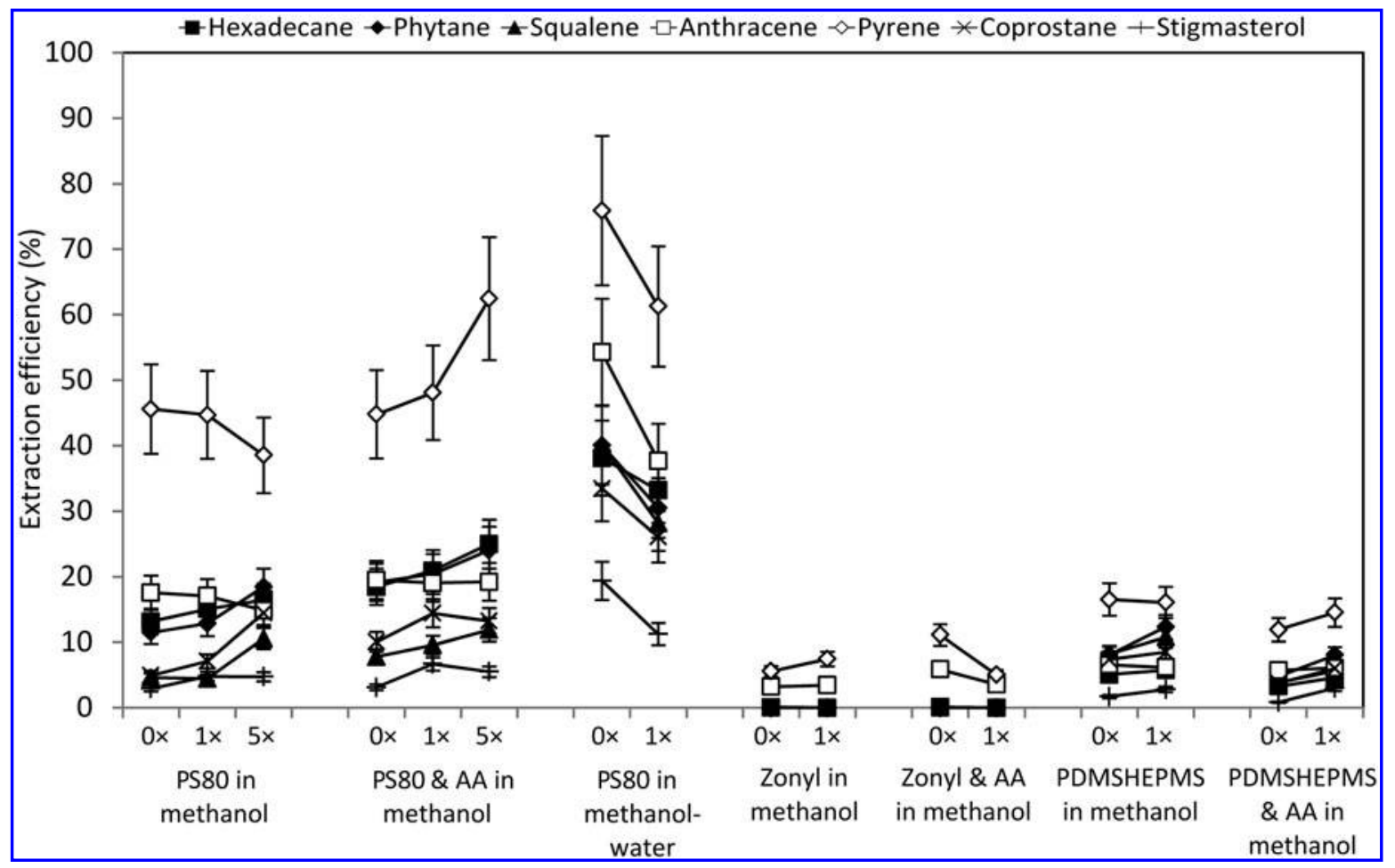

FIG. 6. Efficiencies of extraction of standards spiked on JSC Mars- 1 using surfactant solutions subjected to $0 \times, 1 \times$, and $5 \times$ relative mission radiation fluences, with $1 \times$ fluence being $6.2 \times 10^{11}$ protons $\mathrm{cm}^{-2}$. AA indicates ascorbic acid. Error bars of $\pm 15 \%$ are derived from the distribution of the recoveries of water-soluble atrazine. While differences in extraction efficiencies using nonirradiated and irradiated solutions are observed, in no case is irradiation associated with a failure of the surfactant solution to extract the spiked standards with a reasonable degree of efficiency. In the case of Zonyl FS-300, both nonirradiated and irradiated samples recorded very low extraction efficiencies, but this effect derives from a Zonyl FS-300 concentration that is too low, rather than from radiolytic degradation of the surfactant solution.

\subsection{Surfactant solution composition}

4.2.1. Selection of a surfactant. High temperatures degrade surfactant solutions. However, cooling a spacecraft illuminated by the Sun in the inner Solar System, particularly when packaged in an aeroshell for entry into an atmosphere from which heat cannot easily escape, can be a challenging task. Therefore, it may be desirable to select a surfactant solution more tolerant of thermal extremes rather than one that offers superior performance but only under specific conditions. The data presented here suggest a choice between PS80 and PDMSHEPMS - the data from Zonyl FS-300 are too uncertain to allow firm conclusions. The data in Figs 3 and 5 indicate that both PS80 and PDMSHEPMS are fairly effective at retaining their ability to extract the organic standards from JSC Mars- 1 up to $20^{\circ} \mathrm{C}$. A comparison of the recoveries of spiked standards by using solutions that possess similar solvents and concentrations of ascorbic acid, but differing in surfactant (e.g., comparing Fig. 3A with Fig. 5A and Fig. 3B with Fig. 5B), shows no uniform advantage for one surfactant over the set of four combinations of solutions.

4.2.2. Selection of a solvent. The surfactant solutions investigated here and elsewhere (e.g., Court et al., 2010, 2012a, 2012b; Sims et al., 2012) have all been a mixture of three components: a 20:80 (v/v) mixture of methanol and water with $1.5 \mathrm{~g} \mathrm{~L}^{-1}$ of a surfactant. It is reasonable to expect that each mixture should experience different stabilities during prolonged storage; hence the choice here of surfactant mixed with both water-methanol and methanol alone (with the water envisaged to be stored separately in the instrument) for the solvents. Inspection of the data presented here indicates that neither solvent has an obvious uniform advantage over the other, with Figs. 3 and 5 revealing some occasions where use of methanol-water results in superior recovery of the standards and other occasions where results are inferior.

In the case of electrical conductivity and $\mathrm{pH}$, the use of water-methanol as a solvent is associated with somewhat acidic solutions that frequently conduct electricity. While these properties do not appear to have clearly influenced the ability of these solutions to extract the standards spiked onto JSC Mars-1, acidity may result in undesirable chemical reactions between the surfactant solution and a sample of martian rock or soil, or indeed between the surfactant solution and parts of the LMC-type instrument itself, such as the antibody assay. Furthermore, the possibility of interference with other instrument measurements should also be considered. For example, a measurement of electrical conductivity or acidity in a surfactant solution after exposure to martian samples may be interpreted in terms of soluble salts such as sulfates or perchlorates, but such an interpretation may be more difficult in the case of a surfactant solution already possessing acidic and electrically conductive properties. Hence, since the data indicate no obvious uniform 
advantage from a particular solvent type, it may be desirable to use a surfactant solution that uses methanol as a solvent, with the water stored elsewhere. However, this may be associated with penalties in instrument mass and volume.

4.2.3. Benefits from ascorbic acid. Ascorbic acid was included in some samples in an attempt to protect against autoxidation and damage from free-radical reaction mechanisms, such as those resulting from the production of hydroxyl radicals during the radiolysis of water. Inspection of the extraction efficiencies when using stored PS80 in Fig. 3 and Table 3 suggests that the presence of ascorbic acid is associated with superior extraction efficiencies at intermediate temperatures, particularly $20^{\circ} \mathrm{C}$. A similar effect is seen with PDMSHEPMS stored in methanol with and without ascorbic acid, but the data for PDMSHEPMS stored in methanol-water are more equivocal, given the error bars of Fig. 5. These data suggest that inclusion of ascorbic acid may aid extraction efficiency by hindering degradation of the surfactant. However, any advantage gained in this fashion must be weighed against possible disadvantages relating to the increase in solution complexity.

Figure 6 and Table 4 show the extraction efficiencies for the surfactant solutions involved in the irradiation experiment. The presence of ascorbic acid and PS80 in methanol is associated with a small general increase in extraction efficiency. However, for Zonyl FS-300 and PDMSHEPMS in methanol, no clear effect is seen, although in the case of Zonyl FS-300 interpretations are again hindered by the very low extraction efficiencies. However, it is difficult to interpret the improved recovery for PS80 solutions containing ascorbic acid in terms of radioprotection, because no coherent relationship is observed between increasing radiation fluence and decreasing recovery of standards. Instead, it seems more likely that if the ascorbic acid is having a beneficial effect in these samples, then it is more related to the effects of oxidation rather than irradiation.

Oxidation can proceed directly via reaction with dissolved or headspace oxygen or via autoxidation of ethylene oxide units (Donbrow, 1987; Yao et al., 2009; Kishore et al., 2011a). The oxygen content of the solutions was minimized via degassing of solvent and purging the headspace of the sample bottles with nitrogen. The ability of the solutions stored at low temperatures to extract the spiked standards at reasonable efficiencies, similar to those obtained by using fresh solutions, indicates that oxidation related to oxygen dissolved in the solvent and present in the headspace is not a significant problem. Autoxidation of ethylene oxide units is the dominant degradation pathway affecting polysorbates below $40^{\circ} \mathrm{C}$ (e.g., Kishore et al., 2011b, and references therein). The ability of antioxidants to protect against autoxidation (Donbrow, 1987) suggests that ascorbic acid may be responsible for observed improvements in extraction efficiency. However, the variable nature of these improvements, seen only in certain solution compositions, suggests that this relationship may be neither reliable nor significant.

Overall, the data suggest that addition of ascorbic acid may have a small preservative effect, hindering the autoxidative degradation of PS80. For the other surfactants, however, the benefits are much more equivocal. The data do not indicate a preservative effect against radiation damage, but this is probably because the radiation doses involved in this experiment were too low to significantly alter the surfactant properties of the solutions. Any protective advantage of ascorbic acid for PS80 solutions must be considered against any drawbacks arising from its presence, such as acidification of the surfactant solution, reactions between an acidic solvent and martian or instrument material, and the likely degradation products of the antioxidant itself.

\subsection{False positives from degradation of surfactants}

The use of an antibody-based assay to detect the presence of organic molecules diagnostic of biology results in several challenges, one of which is a potential lack of specificity of the antibodies. It is desirable to produce an antibody that reacts only with a specific molecule while ignoring other species that have similar structures. However, some degree of cross-reactivity should be expected and accounted for in the instrument design. It is therefore important that the surfactant chosen does not include impurities or produce degradation products sufficiently similar to biomarkers that cross-reaction with the antibodies can result in false positives. It is well known that commercially available PS80 is an impure mixture, containing abundant contaminants including isosorbide polyoxyethylene fatty acid esters (Ayorinde et al., 2000; Frison-Norrie and Sporns, 2001; Kishore et al., 2011a), the presence of which may be able to induce a false-positive detection of organic matter in a martian sample via crossreactivity with biomarkers. While purification of a surfactant to remove troublesome contaminants on Earth can be addressed during construction of such an instrument, the problem of degradation of the surfactant en route to Mars is more challenging.

For Zonyl FS-300 and PDMSHEPMS, this issue of crossreactivity of antibodies to surfactant degradation products appears to be insignificant. Zonyl FS-300 and PDMSHEPMS consist of polyoxyethylene chains attached to fluorocarbon and siloxane chains, respectively (Fig. 1). It does not seem likely that degradation of these molecules would be capable of producing compounds sufficiently similar to a targeted biomarker to result in antibody cross-reactivity. For example, a fluoroalkane molecule formed by cleavage of the fluorocarbon chain from the Zonyl FS-300 molecule possesses a helical carbon backbone, relative to the straighter carbon chain of an alkane such as hexadecane.

Polysorbate 80, however, is more of a problem. PS80 consists of a hydrophilic polyethoxylated sorbitan core with an attached hydrophobic oleic acid chain (Fig. 1). It is possible for degradation to separate the sorbitan core from the fatty acid side chain. While the sorbitan core is not expected to pose any cross-reactivity problems, the oleic acid chain is more worrying. Long-chain carboxylic acids are potential biomarkers themselves, as are the straight hydrocarbon chains that remain after loss of their carboxylic acid group, while degradation of ascorbic acid could produce small ketones and alcohols that could be mistaken for the products of the oxidation of martian or meteoritic organic matter (e.g., Benner et al., 2000).

Therefore, great care should be taken to ensure that an instrument seeking to use surfactant-based solvents to extract organic matter in martian environments is not sensitive to the breakdown products of the surfactant and any additives used. This suggests that an inorganic surfactant such as 
the fluorosurfactant Zonyl FS-300 or the polysiloxane PDMSHEPMS is more appropriate than a polysorbate, and argues for caution when considering the inclusion of an antioxidant such as ascorbic acid.

\section{Conclusions}

The radiolytic and thermal degradation of surfactant solutions involved in an instrument designed to detect organic matter on Mars has been simulated by using cyclotron proton irradiation and storage at various temperatures for up to 429 days. Results indicate that neither the $1 \times$ nor $5 \times$ baseline proton fluences $\left(6.2 \times 10^{11}\right.$ and $31 \times 10^{11}$ protons $\mathrm{cm}^{-2}$ ) induce significant changes in solution $\mathrm{pH}$ or electrical conductivity, nor do they significantly damage the ability of the surfactant solutions to extract the standards spiked onto samples of JSC Mars-1. Irradiation of surfactant solutions by the cosmic and solar particle fluxes, both during the flight to Mars and subsequently on the surface, is therefore not expected to impact the ability of surfactant solution to extract organic matter from samples of martian rock or soil.

The storage experiments addressed questions of surfactant type, solvent, the value of including ascorbic acid, and the temperature of storage. The data indicate that the dominant factor influencing the ability of the surfactant solutions to extract organic standards spiked on JSC Mars-1 is temperature. In general, the data indicate the surfactant solutions should be stored at as low a temperature as is feasible. The best extraction efficiencies were obtained for solutions stored at $-20^{\circ} \mathrm{C}$, while storage at $60^{\circ} \mathrm{C}$ was associated with very low extraction efficiencies, indicating severely degraded surfactant solutions.

The presence of ascorbic acid was sometimes associated with improvements in the recovery of the spiked standards, but the relationship was not ubiquitous, and its cause and significance are not clear. The inclusion of ascorbic acid in surfactant solutions also results in changes in acidity and electrical conductivity alongside the additional complexity of adding another organic compound to the solvent mixture, with potential implications for cross-reactivity of antibodies. Overall, therefore, it seems wiser to keep the surfactant solution as simple as possible and to avoid routinely adding antioxidants such as ascorbic acid without compelling reason. Similarly, storage of the surfactant in methanol offers no unequivocal advantage over storage in 20:80 (v/v) methanolwater. While changes in extraction efficiency are apparent, there is no uniform relationship between solvent type and recovery of the standards across the range of solution compositions tested. Overall, it may be stated that the nature of the solvent and the presence of ascorbic acids are minor controls, relative to temperature.

Polysorbate 80 and PDMSHEPMS show generally similar relationships with variations in storage temperature, with solutions stored at $-20^{\circ} \mathrm{C}$ both showing good recoveries of spiked standards after prolonged storage, with no clear evidence favoring one surfactant over the other. However, the organic nature of PS80, and its potential for degradation resulting in contamination of the surfactant solution by organic species that could be mistaken as matter indigenous to Mars and therefore be capable of provoking a false-positive result, suggests that
PDMSHEPMS would be a better choice for a future surfactant-based solvent-extraction instrument. Interpretation of the data from Zonyl FS-300 was hindered by the low extraction efficiencies reported in all cases.

\section{Acknowledgments}

This work was supported by the UK Space Agency. We would like to thank the University of Birmingham, Professor David Parker, and Dr Michael Smith for their assistance with use of the Scanditronix MC40 cyclotron. We would like to thank the reviewers for their thoughtful comments that greatly improved this work.

\section{Author Disclosure Statement}

No competing financial interests exist.

\section{Abbreviations}

DCM, dichloromethane; GC-MS, gas chromatographmass spectrometer; GCR, galactic cosmic ray; LMC, Life Marker Chip; PDMSHEPMS, poly[dimethylsiloxane-co-[3(2-(2-hydroxyethoxy)ethoxy)propyl]methylsiloxane]; PS80, polysorbate 80; PTFE, polytetrafluoroethylene; RO, reverse osmosis.

\section{References}

Aliste, A.J. and Del Mastro, N.L. (2004) Ascorbic acid as radiation protector on polysaccharides used in food industry. Colloids Surf A Physicochem Eng Asp 249:131-133.

Allen, C.C., Jager, K.M., Morris, R.V., Lindstrom, D.J., Lindstrom, M.M., and Lockwood, J.P. (1998) JSC Mars-1: a martian soil simulant. In Space '98: The Sixth International Conference and Exposition on Engineering, Construction, and Operations in Space, edited by R.G. Galloway and S. Lokajs, American Society of Civil Engineers, Reston, VA, pp 469-476.

Amashukeli, X., Pelletier, C.C., Kirby, J.P., and Grunthaner, F.J. (2007) Subcritical water extraction of amino acids from Atacama Desert soils. J Geophys Res Biogeosciences 112, doi:10.1029/2006JG000308.

Amashukeli, X., Grunthaner, F.J., Patrick, S.B., and Yung, P.T. (2008) Subcritical water extractor for Mars analog soil analysis. Astrobiology 8:597-604.

Aubrey, A.D., Chalmers, J.H., Bada, J.L., Grunthaner, F.J., Amashukeli, X., Willis, P., Skelley, A.M., Mathies, R.A., Quinn, R.C., Zent, A.P., Ehrenfreund, P., Amundson, R., Glavin, D.P., Botta, O., Barron, L., Blaney, D.L., Clark, B.C., Coleman, M., Hofmann, B.A., Josset, J.L., Rettberg, P., Ride, S., Robert, F., Sephton, M.A., and Yen, A. (2008) The Urey instrument: an advanced in situ organic and oxidant detector for Mars exploration. Astrobiology 8:583-595.

Ayorinde, F.O., Gelain, S.V., Johnson, J.H., and Wan, L.W. (2000) Analysis of some commercial polysorbate formulations using matrix-assisted laser desorption/ionization timeof-flight mass spectrometry. Rapid Commun Mass Spectrom 14: 2116-2124.

Bada, J.L., Sephton, M.A., Ehrenfreund, P., Mathies, R.A., Skelley, A.M., Grunthaner, F.J., Zent, A.P., Quinn, R.C., Josset, J.L., Robert, F., Botta, O., and Glavin, D.P. (2005) New strategies to detect life on Mars. Astronomy \& Geophysics 46:26-27.

Bates, T.R., Nighting, Ch., and Dixon, E. (1973) Kinetics of hydrolysis of polyoxyethylene (20) sorbitan fatty-acid ester surfactants. J Pharm Pharmacol 25:470-477. 
Benner, S.A., Devine, K.G., Matveeva, L.N., and Powell, D.H. (2000) The missing organic molecules on Mars. Proc Natl Acad Sci USA 97:2425-2430.

Benton, E.R. and Benton, E.V. (2001) Space radiation dosimetry in low-Earth orbit and beyond. Nucl Instrum Methods Phys Res B 184:255-294.

Biemann, K., Oro, J., Toulmin, P., Orgel, L.E., Nier, A.O., Anderson, D.M., Flory, D., Diaz, A.V., Rushneck, D.R., and Simmonds, P.G. (1977) The search for organic substances and inorganic volatile compounds in the surface of Mars. $J$ Geophys Res 82:4641-4658.

Blanco, Y., Rivas, L.A., Ruiz-Bermejo, M., and Parro, V. (2013) Immunological detection of mellitic acid in the Atacama Desert: implication for organics detection on Mars. Icarus 224:326-333.

Carr, M.H. and Head, J.W. (2010) Geologic history of Mars. Earth Planet Sci Lett 294:185-203.

Catling, D.C., Claire, M.W., Zahnle, K.J., Quinn, R.C., Clark, B.C., Hecht, M.H., and Kounaves, S. (2010) Atmospheric origins of perchlorate on Mars and in the Atacama. J Geophys Res Planets 115, doi:10.1029/2009JE003425.

Choi, J.I., Lee, H.S., Kim, J.H., Lee, K.W., Lee, J.W., Seo, S.J., Kang, K.W., and Byun, M.W. (2008) Controlling the radiation degradation of carboxymethylcellulose solution. Polym Degrad Stab 93:310-315.

Court, R.W., Baki, A.O., Sims, M.R., Cullen, D., and Sephton, M.A. (2010) Novel solvent systems for in-situ extraterrestrial sample analysis. Planet Space Sci 58:1470-1474.

Court, R.W., Rix, C.S., Sims, M.R., Cullen, D.C., and Sephton, M.A. (2012a) Extraction of polar and nonpolar biomarkers from the martian soil using aqueous surfactant solutions. Planet Space Sci 67:109-118.

Court, R.W., Sims, M.R., Cullen, D.C., and Sephton, M.A. (2012b) Potential failure of life detection experiments on Mars resulting from adsorption of organic compounds on to common instrument materials. Planet Space Sci 73:262-270.

Dartnell, L.R., Desorgher, L., Ward, J.M., and Coates, A.J. (2007) Modelling the surface and subsurface martian radiation environment: implications for astrobiology. Geophys Res Lett 34, doi:10.1029/2006GL027494.

Derveni, M., Hands, A., Allen, M., Sims, M.R., and Cullen, D.C. (2012) Effects of simulated space radiation on immunoassay components for life-detection experiments in planetary exploration missions. Astrobiology 12:718-729.

Derveni, M., Allen, M., Sawakuchi, G.O., Yukihara, E.G., Richter, L., Sims, M.R., and Cullen, D.C. (2013) Survivability of immunoassay reagents exposed to the space radiation environment on board the ESA BIOPAN-6 platform as a prelude to performing immunoassays on Mars. Astrobiology 13:92-102.

Donbrow, M. (1987) Stability of the polyoxyethylene chain. In Nonionic Surfactants: Physical Chemistry, edited by M.J. Schicks, Marcel Dekker, Inc., New York, pp 1060-1065.

Donbrow, M., Azaz, E., and Pillersdorf, A. (1978) Autoxidation of polysorbates. J Pharm Sci 67:1676-1681.

Duchesne, J., Gilles, R., and Mosora, F. (1975) Effect of antioxidant substances on the level of free organic radicals naturally present in the rat diaphragm. $\underline{C R \text { Acad Sci Hebd }}$ Seances Acad Sci D 281:945-947.

DuPont. (2005) DuPont Zonyl FS-300 fluorosurfactant. DuPont, Wilmington, DE.

El-Nahas, S.M., Mattar, F.E., and Mohamed, A.A. (1993) Radioprotective effect of vitamins C and E. Mutat Res 301:143-147.
Farley, K.A., Malespin, C., Mahaffy, P., Grotzinger, J.P., Vasconcelos, P.M., Milliken, R.E., Malin, M., Edgett, K.S., Pavlov, A.A., Hurowitz, J.A., Grant, J.A., Miller, H.B., Arvidson, R., Beegle, L., Calef, F., Conrad, P.G., Dietrich, W.E., Eigenbrode, J., Gellert, R., Gupta, S., Hamilton, V., Hassler, D.M., Lewis, K.W., McLennan, S.M., Ming, D., Navarro-González, R., Schwenzer, S.P., Steele, A., Stolper, E.M., Sumner, D.Y., Vaniman, D., Vasavada, A., Williford, K., Wimmer-Schweingruber, R.F., and the MSL Science Team. (2014) In situ radiometric and exposure age dating of the martian surface. Science 343, doi:10.1126/science.1247166.

Flynn, G.J. (1996) The delivery of organic matter from asteroids and comets to the early surface of Mars. Earth Moon Planets 72:469-474.

Frison-Norrie, S. and Sporns, P. (2001) Investigating the molecular heterogeneity of polysorbate emulsifiers by MALDITOF MS. J Agric Food Chem 49:3335-3340.

Gilardi-Lorenz, F.I. (2006) Analytical Characterisation of the Excipient Polysorbate 80, Swiss Federal Institute of Technology, Zurich, Switzerland.

Glavin, D.P., Freissinet, C., Miller, K.E., Eigenbrode, J.L., Brunner, A.E., Buch, A., Sutter, B., Archer, P.D., Atreya, S.K., Brinckerhoff, W.B., Cabane, M., Coll, P., Conrad, P.G., Coscia, D., Dworkin, J.P., Franz, H.B., Grotzinger, J.P., Leshin, L.A., Martin, M.G., McKay, C., Ming, D.W., Navarro-González, R., Pavlov, A., Steele, A., Summons, R.E., Szopa, C., Teinturier, S., and Mahaffy, P.R. (2013) Evidence for perchlorates and the origin of chlorinated hydrocarbons detected by SAM at the Rocknest aeolian deposit in Gale Crater. J Geophys Res Planets 118:1955-1973. Hassler, D.M., Zeitlin, C., Wimmer-Schweingruber, R.F., Ehresmann, B., Rafkin, S., Eigenbrode, J.L., Brinza, D.E., Weigle, G., Bottcher, S., Bohm, E., Zeitlin, C., WimmerSchweingruber, R.F., Ehresmann, B., Rafkin, S., Eigenbrode, J.L., Brinza, D.E., Weigle, G., Böttcher, S., Böhm, E., Burmeister, S., Guo, J., Köhler, J., Martin, C., Reitz, G., Cucinotta, F.A., Kim, M.H., Grinspoon, D., Bullock, M.A., Posner, A., Gómez-Elvira, J., Vasavada, A., Grotzinger, J.P., and the MSL Science Team. (2014) Mars' surface radiation environment measured with the Mars Science Laboratory's Curiosity rover. Science 343, doi:10.1126/science.1244797.

Hecht, M.H., Kounaves, S.P., Quinn, R.C., West, S.J., Young, S.M.M., Ming, D.W., Catling, D.C., Clark, B.C., Boynton, W.V., Hoffman, J., Kounaves, S.P., Quinn, R.C., West, S.J., Young, S.M., Ming, D.W., Catling, D.C., Clark, B.C., Boynton, W.V., Hoffman, J., Deflores, L.P., Gospodinova, K., Kapit, J., and Smith, P.H. (2009) Detection of perchlorate and the soluble chemistry of martian soil at the Phoenix lander site. Science 325:64-67.

Kerwin, B.A. (2008) Polysorbates 20 and 80 used in the formulation of protein biotherapeutics: structure and degradation pathways. J Pharm Sci 97:2924-2935.

Kim, Y.S., Wo, K.P., Maity, S., Atreya, S.K., and Kaiser, R.I. (2013) Radiation-induced formation of chlorine oxides and their potential role in the origin of martian perchlorates. $\underline{\mathrm{Jm}}$ Chem Soc 135:4910-4913.

Kishore, R.S.K., Kiese, S., Fischer, S., Pappenberger, A., Grauschopf, U., and Mahler, H.C. (2011a) The degradation of polysorbates 20 and 80 and its potential impact on the stability of biotherapeutics. Pharm Res 28:1194-1210.

Kishore, R.S.K., Pappenberger, A., Dauphin, I.B., Ross, A., Buergi, B., Staempfli, A., and Mahler, H.C. (2011b) Degradation of polysorbates 20 and 80: studies on thermal autoxidation and hydrolysis. J Pharm Sci 100:721-731. 
Klein, H.P. (1978) The Viking biological experiments on Mars. Icarus 34:666-674.

Kminek, G. and Bada, J.L. (2006) The effect of ionizing radiation on the preservation of amino acids on Mars. Earth Planet Sci Lett 245:1-5.

Kolb, C., Lammer, H., Ellery, A., Edwards, H.G.M., Cockell, C.S., and Patel, M.R. (2002) The martian oxygen surface sink and its implications for the oxidant extinction depth. In Proceedings of the $2^{\text {nd }}$ European Workshop on Exo/Astrobiology, ESA SP-518, edited by H. Sawaya-Lacostes, ESA Publications Division, Graz, Austria, pp 181-184.

Kounaves, S.P., Hecht, M.H., Kapit, J., Gospodinova, K., DeFlores, L., Quinn, R.C., Boynton, W.V., Clark, B.C., Catling, D.C., Hredzak, P., Ming, D.W., Moore, Q., Shusterman, J., Stroble, S., West, S.J., and Young, S.M.M. (2010) Wet Chemistry experiments on the 2007 Phoenix Mars Scout Lander mission: data analysis and results. J Geophys Res Planets 115, doi:10.1029/2009JE003424.

Le Postollec, A., Incerti, S., Dobrijevic, M., Desorgher, L., Santin, G., Moretto, P., Vandenabeele-Trambouze, O., Coussot, G., Dartnell, L., and Nieminen, P. (2009) Monte Carlo simulation of the radiation environment encountered by a biochip during a space mission to Mars. Astrobiology 9:311-323.

Leshin, L.A., Mahaffy, P.R., Webster, C.R., Cabane, M., Coll, P., Conrad, P.G., Archer, P.D., Atreya, S.K., Brunner, A.E., Buch, A., Eigenbrode, J.L., Flesch, G.J., Franz, H.B., Freissinet, C., Glavin, D.P., McAdam, A.C., Miller, K.E., Ming, D.W., Morris, R.V., Navarro-González, R., Niles, P.B., Owen, T., Pepin, R.O., Squyres, S., Steele, A., Stern, J.C., Summons, R.E., Sumner, D.Y., Sutter, B., Szopa, C., Teinturier, S., Trainer, M.G., Wray, J.J., Grotzinger, J.P., and the MSL Science Team. (2013) Volatile, isotope, and organic analysis of martian fines with the Mars Curiosity Rover. Science 341, doi:10.1126/science.1238937.

Marquette, C.A. and Blum, L.J. (2006) State of the art and recent advances in immunoanalytical systems. Biosens Bioelectron 21:1424-1433.

Martinez, G.M. and Renno, N.O. (2013) Water and brines on Mars: current evidence and implications for MSL. Space Sci Rev 175:29-51.

Ming, D.W., Archer, P.D., Jr., Glavin, D.P., Eigenbrode, J.L., Franz, H.B., Sutter, B., Brunner, A.E., Stern, J.C., Freissinet, C., McAdam, A.C., Mahaffy, P.R., Cabane, M., Coll, P., Campbell, J.L., Atreya, S.K., Niles, P.B., Bell, J.F., III, Bish, D.L., Brinckerhoff, W.B., Buch, A., Conrad, P.G., Des Marais, D.J., Ehlmann, B.L., Fairén, A.G., Farley, K., Flesch, G.J., Francois, P., Gellert, R., Grant, J.A., Grotzinger, J.P., Gupta, S., Herkenhoff, K.E., Hurowitz, J.A., Leshin, L.A., Lewis, K.W., McLennan, S.M., Miller, K.E., Moersch, J., Morris, R.V., Navarro-González, R., Pavlov, A.A., Perrett, G.M., Pradler, I., Squyres, S.W., Summons, R.E., Steele, A., Stolper, E.M., Sumner, D.Y., Szopa, C., Teinturier, S., Trainer, M.G., Treiman, A.H., Vaniman, D.T., Vasavada, A.R., Webster, C.R., Wray, J.J., Yingst, R.A., and the MSL Science Team. (2014) Volatile and organic compositions of sedimentary rocks in Yellowknife Bay, Gale Crater, Mars. Science 343, doi:10.1126/science.1245267.

Nair, C.K.K., Parida, D.K., and Nomura, T. (2001) Radioprotectors in radiotherapy. J Radiat Res 42:21-37.

Navarro-González, R., Vargas, E., de la Rosa, J., Raga, A.C., and McKay, C.P. (2010) Reanalysis of the Viking results suggests perchlorate and organics at midlatitudes on Mars. $J$ Geophys Res Planets 115, doi:10.1029/2010JE003599.
Parnell, J., Cullen, D., Sims, M.R., Bowden, S., Cockell, C.S., Court, R.W., Ehrenfreund, P., Gaubert, F., Grant, W., Parro, V., Rohmer, M., Sephton, M., Stan-Lotter, H., Steele, A., Toporski, J., and Vago, J. (2007) Searching for life on Mars: selection of molecular targets for ESA's Aurora ExoMars mission. Astrobiology 7:578-604.

Parro, V., Rodríguez-Manfredi, J.A., Briones, C., Compostizo, C., Herrero, P.L., Vez, E., Sebastián, E., Moreno-Paz, M., Garcia-Villadangos, M., Fernández-Calvo, P., GonzálezToril, E., Pérez-Mercader, J., Fernández-Remolar, D., and Gómez-Elvira, J. (2005) Instrument development to search for biomarkers on Mars: terrestrial acidophile, iron-powered chemolithoautotrophic communities as model systems. Planet Space Sci 53:729-737.

Parro, V., de Diego-Castilla, G., Moreno-Paz, M., Blanco, Y., Cruz-Gil, P., Rodríguez-Manfredi, J.A., Fernández-Remolar, D., Gómez, F., Gómez, M.J., Rivas, L.A., Demergasso, C., Echeverría, A., Urtuvia, V.N., Ruiz-Bermejo, M., GarcíaVilladangos, M., Postigo, M., Sánchez-Román, M., ChongDíaz, G., and Gómez-Elvira, J. (2011a) A microbial oasis in the hypersaline Atacama subsurface discovered by a life detector chip: implications for the search for life on Mars. Astrobiology 11:969-996.

Parro, V., de Diego-Castilla, G., Rodríguez-Manfredi, J.A., Rivas, L.A., Blanco-López, Y., Sebastián, E., Romeral, J., Compostizo, C., Herrero, P.L., García-Marín, A., MorenoPaz, M., García-Villadangos, M., Cruz-Gil, P., Peinado, V., Martín-Soler, J., Pérez-Mercader, J., and Gómez-Elvira, J. (2011b) SOLID3: a multiplex antibody microarray-based optical sensor instrument for in situ life detection in planetary exploration. Astrobiology 11:15-28.

Pavlov, A.A., Vasilyev, G., Ostryakov, V.M., Pavlov, A.K., and Mahaffy, P. (2012) Degradation of the organic molecules in the shallow subsurface of Mars due to irradiation by cosmic rays. Geophys Res Lett 39, doi:10.1029/2012GL052166.

Quinn, R.C., Martucci, H.F.H., Miller, S.R., Bryson, C.E., Grunthaner, F.J., and Grunthaner, P.J. (2013) Perchlorate radiolysis on Mars and the origin of martian soil reactivity. Astrobiology 13:515-520.

Ryan, J.M., Lockwood, J.A., and Debrunner, H. (1999) Solar energetic particles. Space Sci Rev 93:35-53.

Schuttlefield, J.D., Sambur, J.B., Gelwicks, M., Eggleston, C.M., and Parkinson, B.A. (2011) Photooxidation of chloride by oxide minerals: implications for perchlorate on Mars. $\underline{\mathrm{JAm}}$ Chem Soc 133:17521-17523.

Schweitzer, M.H., Wittmeyer, J., Avci, R., and Pincus, S. (2005) Experimental support for an immunological approach to the search for life on other planets. Astrobiology 5:30-47. Sephton, M.A., Sims, M.R., Court, R.W., Luong, D., and Cullen, D.C. (2013) Searching for biomolecules on Mars: considerations for operation of a Life Marker Chip instrument. Planet Space Sci 86:66-74.

Sereewatthanawut, I., Prapintip, S., Watchiraruji, K., Goto, M., Sasaki, M., and Shotipruk, A. (2008) Extraction of protein and amino acids from deoiled rice bran by subcritical water hydrolysis. Bioresour Technol 99:555-561.

Shadyro, O., Lagutin, P., Edimecheva, I., Brinkevich, S., and Kagiya, T. (2008) Protective effects of vitamin glycosides on gamma-radiation and $\mathrm{H}_{2} \mathrm{O}_{2}$-induced decomposition of thymine in aqueous solutions. $J$ Radiat Res 49:431-435.

Sims, M.R., Cullen, D.C., Rix, C.S., Buckley, A., Derveni, M., Evans, D., García-Con, L.M., Rhodes, A., Rato, C.C., Stefinovic, M., Sephton, M.A., Court, R.W., Bulloch, C., Kitchingman, I., Ali, Z., Pullan, D., Holt, J., Blake, O., Sykes, J., 
Samara-Ratna, P., Canali, M., Borst, G., Leeuwis, H., Prak, A., Norfini, A., Geraci, E., Tavanti, M., Brucato, J., and Holm, N. (2012) Development status of the Life Marker Chip instrument for ExoMars. Planet Space Sci 72:129-137.

Steele, A., Toporski, J., McKay, D.S., Schweitzer, M., Pincus, S., Perez-Mercader, J., and Parro Garcia, V. (2001) Microarray assays for Solar System exploration. Astrobiology 1:214.

Steininger, H., Goesmann, F., and Goetz, W. (2012) Influence of magnesium perchlorate on the pyrolysis of organic compounds in Mars analogue soils. Planet Space Sci 71:9-17.

Villanueva, G.L., Mumma, M.J., Novak, R.E., Radeva, Y.L., Kaufl, H.U., Smette, A., Tokunaga, A., Khayat, A., Encrenaz, T., and Hartogh, P. (2013) A sensitive search for organics $\left(\mathrm{CH}_{4}, \mathrm{CH}_{3} \mathrm{OH}, \mathrm{H}_{2} \mathrm{CO}, \mathrm{C}_{2} \mathrm{H}_{6}, \mathrm{C}_{2} \mathrm{H}_{2}, \mathrm{C}_{2} \mathrm{H}_{4}\right)$, hydroperoxyl $\left(\mathrm{HO}_{2}\right)$, nitrogen compounds $\left(\mathrm{N}_{2} \mathrm{O}, \mathrm{NH}_{3}, \mathrm{HCN}\right)$ and chlorine species $\left(\mathrm{HCl}, \mathrm{CH}_{3} \mathrm{Cl}\right)$ on Mars using ground-based highresolution infrared spectroscopy. Icarus 223:11-27.

Wang, J. (2006) Electrochemical biosensors: towards point-ofcare cancer diagnostics. Biosens Bioelectron 21:1887-1892.

Wilson, R.L. (1983) Free radical repair mechanisms and the interaction of glutathion and vitamin $\mathrm{C}$ and E. In Radioprotectors and Anticarcinogens, edited by O.F. Nyga and M.G. Simics, Academic Press, New York, pp 1-23.

Yao, J., Dokuru, D.K., Noestheden, M., Park, S.S., Kerwin, B.A., Jona, J., Ostovic, D., and Reid, D.L. (2009) A quanti- tative kinetic study of polysorbate autoxidation: the role of unsaturated fatty acid ester substituents. Pharm Res 26:23032313.

Yen, A.S., Kim, S.S., Hecht, M.H., Frant, M.S., and Murray, B. (2000) Evidence that the reactivity of the martian soil is due to superoxide ions. Science 289:1909-1912.

Zent, A.P. (1998) On the thickness of the oxidized layer of the martian regolith. J Geophys Res Planets 103:31491-31498.

Zent, A.P. and McKay, C.P. (1994) The chemical reactivity of the martian soil and implications for future missions. Icarus 108:146-157.

Address correspondence to: Richard W. Court Department of Earth Science and Engineering South Kensington Campus Imperial College London London, SW7 $2 A Z$

$U K$

E-mail: r.court@imperial.ac.uk

Submitted 29 September 2013 Accepted 21 June 2014 